\title{
SOBRE LA SEGUNDA LEGACIÓN EN ESPAÑA DEL CARDENAL GUIDO DE BOULOGNE (1372-1373)
}

\author{
POR \\ PABlo MARTín PRIETO \\ Universidad Complutense de Madrid \\ pablomartinprieto@ghis.ucm.es
}

\begin{abstract}
RESUMEN
El presente trabajo pretende dibujar un panorama de la misión confiada por el papa Gregorio XI al cardenal Guido de Boulogne, cuando lo envió a una segunda legación en los reinos hispanos en 1372-1373. Allí, el legado se ocupó principalmente de las negociaciones de paz entre Castilla, Portugal, Navarra y Aragón, sin descuidar otros asuntos de su agenda diplomática, relacionados con una cierta variedad de problemas, como cuestiones de disciplina clerical, la necesidad de llegar a un acuerdo final entre Castilla y el Papado sobre la suerte de los bienes que fueron de la orden templaria, o algunos temas propuestos por diferentes instancias del clero local, entre otros. El hilo conductor de nuestra investigación viene dado por una selección significativa de documentos procedentes de los archivos vaticanos, de los que se da una muestra en el apéndice documental.
\end{abstract}

PALABRAS ClAVE: Papado, Castilla, Portugal, Navarra, Aragón, Guido de Boulogne

\section{ON THE SECOND SPANISH LEGATION OF CARDINAL GUI DE BOULOGNE (1372-1373)}

\begin{abstract}
This paper aims to cast a general view over the mission entrusted by Pope Gregoire XI to the cardinal Gui de Boulogne, sent for the second time as a legate to the Spanish kingdoms in 1372-1373. There he kept primarily busy with the negotiations of peace between Castile, Portugal, Navarre and Aragón, but there were other issues in his diplomatic agenda as well, related to a variety of topics, including some attention to clerical discipline matters, the need to find a final settlement between Castile and the Papacy on behalf of the destiny of the late Templar order's properties, and also some causes raised to him by several local clerical institutions. The analysis of a significant selection of documentation from the Vatican archives provides the main shape to our work (with some of them edited in our appendices).
\end{abstract}

KEY WORDS: Papacy, Castile, Portugal, Navarre, Aragón, Gui de Boulogne.

Recibido/Received 17-01-2011

Aceptado/Accepted 10-07-2013

En los últimos tiempos, ${ }^{1}$ y desde distintos ámbitos, se ha dedicado mucho esfuerzo y considerable atención a procurar establecer marcos conceptuales, visiones panorámicas y síntesis parciales acerca de la evolución de las relaciones entre la Iglesia latina bajomedieval y las distintas estructuras políticas de la época, a las que fundadamente se considera directas precursoras del Estado moderno, entendido en su acepción más usual. Particular interés reviste, en este respecto, el seguimiento de las relaciones entabladas al más alto nivel -esto es, entre el Pontificado y las distintas

1 El presente trabajo se enmarca dentro del proyecto de investigación de la Secretaría de Estado de Investigación, Desarrollo e Innovación "Prácticas de comunicación y negociación en las relaciones de consenso y pacto de la cultura política castellana, ca. 1230-1504", HAR2013-42211-P. monarquías europeas-, y dentro de esta línea temática adquiere singular relieve el estudio de las sucesivas misiones diplomáticas y legaciones a través de las cuales los pontífices influyeron, intervinieron o mediaron en los asuntos internos de cada país, o en las relaciones-especialmente en los conflictos- entre unos y otros.

Concretamente, por lo que respecta al estudio de las legaciones dirigidas por los pontífices a los reinos ibéricos, se han publicado tanto contribuciones parciales consagradas en especial a cada una de estas misiones, como esclarecedoras visiones de conjunto que facilitan conclusiones sobre periodos enteros. ${ }^{2}$ Por más de un motivo, los

2 Entre las primeras podemos citar los trabajos clásicos: Zunzunegui Aramburu, J. 1960. "La misión del obispo de Senez al reino de Castilla 
esfuerzos diplomáticos del Pontificado hallaron en la península Ibérica, a lo largo del siglo XIV, un centro de atención particularmente intensa. Las convulsiones y azares de los conflictos bélicos entre los distintos reinos y los cambios dinásticos verificados al frente de dos de ellos -Castilla y Portugal- dan el tono de una época de profundas transformaciones, en la que la mediación del Papado para facilitar la paz o atenuar los efectos de la guerra, así como su intervención en defensa de intereses más propiamente eclesiásticos, se substanció frecuentemente en el envío de diplomáticos de notable relieve por parte de la Santa Sede. Entre las personalidades de altura a las que el Pontificado confió misiones importantes cerca de los reyes peninsulares, destaca con brillo propio la figura del cardenal Guido (Gui) de Boulogne, uno de los más influyentes príncipes de la Iglesia en su tiempo, cuya primera legación en España en tiempos de la llamada guerra de los dos Pedros ya fue en su día objeto de un estudio monográfico debido a José María Mendi. ${ }^{3}$ Más recientemente, en una obra de síntesis, José Manuel Nieto Soria resumió con claridad ejemplar lo esencial de la agenda y los tiempos de la segunda legación hispana de este prelado, prolongada desde 1372 hasta su fallecimiento en $1373 .{ }^{4}$ El propósito de nuestro estudio es retomar esta segunda legación hispana del cardenal de Boulogne, al objeto de precisar y ampliar su desarrollo, tomando como base principal una muestra del volumen de documentación pontificia generada al hilo de dicha misión, cuya huella se conserva en los registros vaticanos.

\section{LA CARRERA DIPLOMÁTICA DE GUIDO DE BOULOGNE}

La trayectoria al servicio de la Iglesia del cardenal Guido de Boulogne (1316-1373) se cuenta, a qué dudarlo, entre las carreras eclesiásticas más ricas y relevantes de todo el siglo XIV. De noble prosapia, hijo del conde Roberto VII de

(1354-1355)". Anthologica Annua 8: 11-42; Zunzunegui Aramburu, J. 1964. "La legación del cardenal Guillermo de la Jugie a Castilla y Aragón (1355-1358)". Anthologica Annua 12: 129-156; Zunzunegui Aramburu, J. 1943. "La legación en España del cardenal Pedro de Luna, 1379-1390". Miscellanea Historiae Pontificiae 7: 83-137. Una visión de síntesis particularmente útil sobre la época Trastámara, referida a nuncios, colectores y legados, se hallará en: Nieto Soria, J. M. 1993. Iglesia y génesis del Estado moderno en Castilla (1369-1480): 60-94. Madrid: Universidad Complutense.

3 Mendi, J. M. 1964. "La primera legación del cardenal Guido de Boulogne a España (1358-1361)”. Scriptorium Victoriense 11: 135-224.

4 Nieto Soria, J. M. 1993: 83-85.

5 Duchesne, F. 1666. Histoire de tous les cardinaux français de naissance, t. II : 334-336. París: impreso por el autor. Baluze, S. 1693. Vitae Paparum Avenionensium, t. I: passim, y cols. 429, 840. París: François Muguet. Eubel, C. 1913. Hierarchia Catholica, t. I: 18. Münster: ex Typis Librariae Regensbergianae. Mollat, G. 1938. "Gui de Boulogne”, en A. BAUDRILLART et alii (eds.), Dictionnaire d'Histoire et de Géographie Écclesiastiques, t. X: cols 101-106. París: Letouzey et Ané; Guillemain, B. 1962. La Cour Pontificale d'Avignon (1309-1376). Étude d'une société: passim, y 249-251. París : Éditions E. de Boccard. Jugie, P. 1986. Le cardinal Gui de Boulogne (1316-1373): biographie et étude d'une familia cardinalice (tesis inédita para la obtención del Diplôme d'archiviste paléographe en la École Nationale des Chartes, 3 vols. Mecanografiados). París : École Nationale des Chartes. Resumen de las conclusiones con el mismo título: Jugie, P. 1986 [2]. Positions des thèses soutenues par les élèves de la promotion de 1986: 83-92. París: École Nationale des Chartes.
Auvernia-Boulogne y María de Flandes, tempranamente destinado al servicio de la Iglesia, contará siempre con excelentes relaciones, llegando a emparentar con la casa real de Francia. ${ }^{6}$ Canónigo de Reims desde 1323, estudia en París con los dominicos, al tiempo que, con el apoyo familiar y de la corona francesa, acumula diversos beneficios eclesiásticos, y en 1340 es nombrado arzobispo de Lyon. ${ }^{7}$ Creado cardenal de Santa Cecilia en 1342, por Clemente $\mathrm{VI},{ }^{8}$ la Curia pontificia comienza a confiarle misiones cada vez más importantes, en las que halla ocasión de probar sus sobresalientes capacidades para el servicio diplomático, en las que no dejarán de apoyarse los sucesivos pontífices. Legado en Hungría e Italia (1348-1350), ${ }^{9}$ al término de esta misión será recompensado con el título de cardenal obispo de Porto y Santa Rufina, que mantendrá hasta su muerte. ${ }^{10}$ Enviado como legado a Francia para mediar por la paz con Inglaterra (1352-1354), ,11 y a España (1358-1361), con la misión principal de procurar la paz entre Castilla y Aragón. ${ }^{12}$ Participa en el conclave de $1362,{ }^{13}$ que elige papa a Urbano V, y desde 1364 figura como decano del colegio cardenalicio. Acompaña a Urbano $\mathrm{V}$ a Italia, asiste a la coronación como emperador de Carlos IV y éste le confía un vicariato imperial en Lucca (1369-1370). ${ }^{14}$ Candidato regular al ministerio petrino, participa en el conclave de 1370, que elige papa a Gregorio XI, a quien Guido impone la tiara pontificia y ordena de sacerdote, convirtiéndose en uno de sus colaboradores más próximos. ${ }^{15}$ Fue precisamente por comisión de Gregorio XI que en 1372 pasó nuevamente a España como legado, para mediar por la paz entre los reinos ibéricos, y allí encontraría la muerte, sin llegar a concluir su misión, hacia finales de 1373.

\section{EL ORIGEN DE LA LEGACIÓN Y LOS PODERES DEL LEGADO}

A comienzos de 1372 , se acumulaban aún mucha tensión, y no pocos agravios sin resolver, en las relaciones entre los reinos ibéricos. La entronización del nuevo poder Trastámara en Castilla trajo consigo una redefinición de los términos en que dichas relaciones venían planteadas, y en este escenario, la paz peninsular distaba de quedar asegurada. Al parecer, fue la insuficiencia de las gestiones

6 Mollat. G. 1938: col. 101; Jugie, P. 1986 [2]: 86.

7 Eubel, C. 1913: 516; Jugie, P. 1986 [2]: 85.

Eubel, C. 1913: 40.

Mollat. G. 1938: cols. 101-102; Jugie, P. 1986 [2]: 86-87; Jugie, P. 1989. "La légation en Hongrie et en Italie du cardinal Gui de Boulogne (1348-1350)". II Santo. Rivista antoniana di storia, dottrina, arte 29: 29-69.

10 Eubel, C. 1913: 37.

11 Mollat, G. 1938: cols. 103-104; Jugie, P. 1986 [2]: 87; Jugie, P. 1987. "L'activité diplomatique du cardinal Gui de Boulogne en France au milieu du XIVe siècle". Bibliothèque de l'École des Chartes 145: 99-127.

12 Mendi, J. M. 1964.

13 Con ocasión del cual, según Froissart, aspiró al Pontificado en rivalidad con el cardenal Talleyrand de Périgord: Mollat, G. 1938: col. 105.

14 Jugie, P. 1991. "Le vicariat impérial du cardinal Gui de Boulogne à Lucques en 1369-1370". Mélanges de l'École Française de Rome. Moyen Âge, Temps Modernes 103/1: 261-357.

15 Mollat, G. 1912. Les papes d'Avignon (1305-1378): 118. París: Librairie Victor Lecoffre. Jugie, P. 1986 [2]: 88. 
diplomáticas de los reinos ibéricos entre sí y respecto del Pontificado, tal como se venían desarrollando por sus canales habituales, la que persuadió a Gregorio XI de tomar la iniciativa y enviar como legado a la península, nuevamente, al cardenal de Boulogne, sin duda la figura más eminente del colegio cardenalicio, en quien tenía depositada gran confianza, y que parecía particularmente capaz para dicha misión, debido a su probado talento diplomático y, muy en especial, por la experiencia directa que poseía de las cosas de España, donde ya había desempeñado una difícil legación de 1358 a 1361.

A comienzos de 1372, Enrique II había enviado a Aviñón, como embajadores, a dos de sus consejeros habituales, Pedro Tenorio, obispo de Coimbra, y su familiar Juan Alfonso, profesor en los dos Derechos, con la misión de preparar la paz con Aragón y Navarra. El 21 de abril de dicho año, Gregorio XI escribe a Enrique II haciéndose eco de esta iniciativa, pero rechaza la mediación de estos embajadores y se los devuelve al rey castellano, porque los poderes que llevaron a la Curia pontificia eran limitados; inmediatamente, tomando la iniciativa, y en el mismo documento, el papa incluye por su cuenta, en la agenda de la negociación, el asunto pendiente de la paz con Portugal, alcanzada precariamente algunos meses atrás, pero que a esas alturas del año parecía ya seriamente amenazada, y anuncia a Enrique Il su decisión de enviar a la península, como legado, al cardenal Guido de Boulogne, para ocuparse de esa compleja misión de paz en varias bandas. ${ }^{16}$

Aun teniendo en cuenta la fraseología habitual de la cancillería pontificia, los términos en los que el papa da cuenta de esta doble decisión son suficientemente expresivos: agradece protocolariamente los servicios de los embajadores enviados por Enrique, pero se los devuelve por la insuficiencia de los poderes que les habían sido concedidos:

"uerum cum tui et regum predictorum ambaxiatores et nuntii mandata habeant limitata [...], predictos ambaxiatores tuos, quorum industriam et solicitudinem multipliciter commendamus, ad serenitatem tuam remittimus"

Al tiempo que alaba las dotes personales del cardenal de Boulogne, cuya experiencia diplomática en suelo hispano se recuerda expresamente:

"uir timoratus et prouidus, nobilitate perspicuus, ac frequenter in arduis etiam in illis partibus conprobatus, clarus scientia, plenusque multis uirtutibus"

Y sin duda pesaron, en la decisión pontificia de enviar a España al miembro más eminente del colegio cardenalicio, tanto el propósito de lograr una interlocución directa al más alto nivel, creíble y eficaz -como los dilatados servicios pasados de Guido parecían ameritar-, como la necesidad de situar al frente de estas negociaciones a alguien bien instruido en los asuntos hispanos, sin duda intrincados y espinosos, por la probada dificultad de conciliar la causa de la paz y la estabilidad entre los reinos ibéricos con la consolidación en Castilla de la nueva dinastía. Esta carta del 21 de abril constituye, así pues, el primer testimonio de la segunda legación hispana

\footnotetext{
16 Véase el documento en el no. 1 de nuestro apéndice documental.
}

del cardenal de Boulogne, y su primera presentación ante el rey de Castilla, aun antes de que el interesado se hiciera cargo de la misma y emprendiera el viaje.

Una vez designado el legado, en la época solía concedérsele plazo de un mes para arreglar sus asuntos antes de emprender el viaje; durante este tiempo, dedicado a labores de intendencia y organización práctica, el nuevo legado tomaba las decisiones necesarias para la movilización de los miembros de su familia que deberían acompañarlo en la legación, ${ }^{17}$ y también se ocupaba de solicitar y obtener del papa las bulas que estimaba podían resultarle más necesarias para facilitar el cumplimiento de su misión. ${ }^{18}$ Concretamente, en el caso de esta segunda legación hispana del cardenal de Boulogne, el pontífice le concedió una serie de facultades por otras tantas bulas, de las cuales algunas se expidieron antes de su partida, y otras más adelante, a medida que el desarrollo de la legación sugería al cardenal la conveniencia de proveerse de nuevos "argumentos negociadores".

Una de las primeras cuestiones organizativas atañía, desde luego, a las previsiones de financiación de la empresa; de acuerdo con el mecanismo habitual, los gastos de la legación corrían a cargo de las contribuciones destinadas al efecto por el clero del territorio donde debía desempeñarse la misión. Así, en una bula de 5 de mayo, el papa fijó pormenorizadamente las cantidades que el clero peninsular debería pagar al legado: contando desde el día en que el cardenal abandonara la Curia y hasta su regreso, el clero navarro contribuiría con cinco florines diarios, el portugués con siete, y los de Castilla y Aragón con veinticuatro florines diarios en cada caso; ${ }^{19}$ asimismo, por otra bula

17 Sobre la organización y la evolución de la familia de este cardenal a lo largo de toda su carrera eclesiástica, véase Jugie, P. 1986: passim. Jugie, P. 1990. "Les familiae cardinalices et leur organisation interne au temps de la papauté d'Avignon: esquisse d'un bilan", en: Le fonctionnement administratif de la Papauté d'Avignon, (Actas de la mesa redonda de la École Française de Rome, Aviñón, enero de 1988): 41-59. Roma: École Française de Rome. Entre los miembros de dicha familia identificados por Jugie que acompañaron al cardenal Guido en su segunda legación a España, pueden citarse el notario apostólico Jean Foucard de la Croix (Johannes Foucardi de Cruce), encargado de redactar algunos de los documentos más importantes del cardenal (Jugie, P. 1991: 276, y nota 40), su limosnero Jean de Moulin-Neuf (Johannes de Molendino Novo: ibidem, p. 277 y nota 41), su médico Pierre Chasle (ibidem, p. 277 y nota 42), su tesorero Nicolas de Clin (Nicolaus de Clino), vice-gerente de la cámara del cardenal durante esta su última legación (ibidem, p. 278 y nota 45), su camarero Gui du Puis (Guido de Puteo), escribano de la cancillería del cardenal durante esta legación (ibidem, p. 278 y nota 46), su doncel Roger de Moulin-Neuf, testamentario del cardenal (ibidem, p. 279 y nota 49), el religioso Bertrand Mitte, testigo del codicilo del testamento del cardenal (ibidem, p. 280 y nota 50), y Guérin d'Arcis (Garinus de Arceyo), canciller del cardenal durante esta legación (ibidem, pp. 280281 y notas 52, 57), a quien volveremos a encontrar, más adelante, en nuestro presente estudio.

18 El ejemplo de un proceso análogo de preparativos, referido a una legación anterior a los reinos españoles, puede seguirse en Zunzunegui Aramburu, J. 1964: 133-134.

19 1372, mayo 5, Aviñón. Gregorio XI anuncia a todo el clero hispano la próxima legación de Guido de Boulogne, y establece la contribución que al clero de cada reino le corresponde para sufragar los gastos de la misión. Conocemos esta bula por la copia coetánea, correspondiente al reino de Navarra: Goñi Gaztambide, J. 1965. Catálogo del Archivo Catedral de Pamplona. Tomo I (829-1500): 352 (doc. no. 1470). Pamplona: Diputación Foral de Navarra. 
dada el mismo día, se autorizaba al cardenal legado a usar de censuras eclesiásticas y otros medios coercitivos contra el clero peninsular, si pareciera necesario recurrir a ello con objeto de vencer cualquier eventual resistencia a pagar las sumas establecidas. ${ }^{20}$

Continuando con los preparativos, el 12 de mayo, cuando el cardenal Guido aún no había partido a su legación, el papa le concede permiso expreso para que pudiera regresar a la Curia en cualquier momento, libremente, aun antes de cumplir la misión; parece razonable suponer que la concesión de esta facultad pudo responder a una iniciativa especial del interesado, a quien quizás inquietaba la perspectiva de que una prolongada ausencia de la Curia pontificia pudiera eclipsar en alguna forma el ascendiente que en ella venía ejerciendo, como decano del colegio cardenalicio y uno de los consejeros principales del pontífice. En cualquier caso, la merced, tal como se recoge en la redacción del documento, se justifica por la necesidad de evitar al nuevo legado y a su familia todo potencial peligro en el desempeño de su misión:

"nos, periculis et malis que propter guerrarum, turbines et malitiam temporis, et uiarum discrimina, et alia diuersimode tibi ac tue familie possent -quod aduertat Dominus- euenire, obuiare uolentes, fraternitati tue ut postquam terminos tue legationis initiaueris, uel etiam anceptis uel non ceptis negociis huius, prout tibi expedire iudebitur, ad nos et sedem apostolicam libere redire ualeas [...] plenam et liberam auctoritate apostolica licentiam elargimus". ${ }^{21}$

Por supuesto, no consta que el precavido cardenal tuviera en momento alguno necesidad de utilizar esta facultad, pues, como es sabido, a la postre sólo la muerte puso fin a esta su última legación.

Hacia el final del plazo acostumbrado de un mes, contado desde el anuncio que el pontífice hiciera a Enrique II el 21 de abril participándole su intención de enviar a España al cardenal Guido como legado, éste fue provisto, el 24 de mayo, con facultad plenaria para proveer canonjías en un importante número de iglesias españolas: en treinta catedrales y otras treinta colegiatas, a razón de una canonjía por iglesia, tal como reza en la bula expedida en esta razón:

"nos, uolentes tibi illa concedere gratiosim, per que aliis possis gratiam impartiri [...], in triginta cathedralibus et aliis triginta collegiatis ecclesiis, infra terminos tue legationis consistentibus, quas duxeris eligendas, uidelicet in

20 1372, mayo 5, Aviñón. Gregorio XI autoriza al cardenal legado Guido de Boulogne a constreñir mediante censuras al clero hispano al pago de los gastos de su legación. La copia coetánea destinada a Navarra, en: Goñi Gaztambide, J. 1965: 352 (doc. no. 1469). No consta que el legado tuviera que hacer uso de esta medida de presión a tal efecto, pero sí que en alguna ocasión hubo de compeler a las autoridades eclesiásticas locales al pago de las cantidades que le adeudaban: así, en el caso del obispo de Pamplona, al que Guido de Boulogne reclamará, el 5 de noviembre de 1372, 450 florines de oro por tres meses de legación en Navarra: Goñi Gaztambide, J. 1965: 353-354 (doc. no. 1476).

21 1372, mayo 12, Sorgues. Gregorio XI concede al cardenal legado Guido de Boulogne permiso para regresar a la Curia cuando lo estimara necesario, una vez hubiera partido a su legación en España: Città del Vaticano, Archivum Secretum Vaticanum, Registra Vaticana (en adelante: ASV, Reg. Vat.), vol. 264, fol. 220v. singulis ecclesiarum ipsarum singulis personis ydoneis, quas etiam ad hoc duxeris eligendas [...], de canonicatibus ipsarum ecclesiarum cum plenitudine iuris canonici, ac personas ipsas in ecclesiis predictas faciendi recipi in canonicos". ${ }^{22}$

En ella se especifica de forma detallada el alcance de esta facultad conferida al legado, quien durante el tiempo de su misión en suelo hispano podría designar libremente a los recipiendarios de estos importantes beneficios, como eficaz medio de mover las voluntades que pareciera necesario asegurar al servicio de sus gestiones. La generosidad del amplio poder que el cardenal legado obtuvo para conferir estos codiciados oficios capitulares entre el clero peninsular habla elocuentemente de la relevancia que se atribuía a su alta misión diplomática.

Más adelante, durante el desarrollo de la legación, cuando el cardenal ya se hallaba en España, recibiría asimismo nuevos poderes por otras bulas que, es fácil suponer, bien pudieron haber sido solicitadas a la Curia expresamente, en momentos estratégicos de la misión, por el mismo Guido: así, el 8 de julio de 1372, se concedió al legado facultad para dispensar del voto de Santiago a cinco miembros de su propia misión (una merced tan concreta sugiere una necesidad específica, atendida por iniciativa del propio interesado); tal vez, al hallarse en España, algunos hombres de la familia del cardenal hicieron voto de peregrinar al sepulcro del Apóstol, pero las necesidades del servicio aconsejó dispensarles del mismo substituyéndolo por alguna otra obra de piedad ("que uotum ipsum commode adimplere non possunt, ac uotum ipsum in alia opera pietatis commutandi"), ${ }^{23}$ a fin de que el legado pudiera seguir contando con ellos si su camino, orientado por su incesante quehacer diplomático, no podía desviarse hacia el rincón del Finisterre.

Por otra bula sobrevenida, a mediados de agosto, se le proveyó del poder de dispensar a cien candidatos a beneficios eclesiásticos de varias formas de defecto de nacimiento que pudieran impedir su investidura. ${ }^{24}$ La índole de esta concesión se compadece bien con el surgimiento de necesidades concretas que pudieron emerger durante el desempeño de la legación; es fácil suponer que pudiera mediar relación entre la facultad que el cardenal legado tenía de conferir beneficios en los capítulos de tantas iglesias catedrales y colegiales, y la necesidad de dispensar a algunos de los candidatos a estas canonjías de impedimentos natales que de otro modo les habrían prohibido ocuparlas.

\section{LA PAZ CON PORTUGAL}

El primer asunto en la agenda de la legación, tal como se plantea ya en la citada bula de 21 de abril de 1372, en la que Gregorio XI anunciaba a Enrique II su decisión de enviar

22 1372, mayo 24, Sorgues. Gregorio XI concede al cardenal legado Guido de Boulogne facultad para proveer treinta canonjías en catedrales y otras treinta en colegiatas de los reinos de España, durante el tiempo de su legación. ASV, Reg.Vat. 264, fols. 126v-127v.

23 Véase el texto en el no. 3 de nuestro apéndice documental.

24 Véase el texto en el no. 4 de nuestro apéndice documental. 
nuevamente al cardenal de Boulogne a España, era afianzar la paz con Portugal. Muerto el rey Pedro de Castilla en 1369 , pronto se vio que las relaciones con Portugal representarían, si no un impedimento, sí un foco de constante tensión en el proceso de consolidación de Enrique II en el trono castellano, pues el rey portugués Fernando I, hostil al Trastámara, elevó la apuesta hasta el punto de reivindicar para sí la corona de Castilla. Superado el año de 1370, que en Castilla fue crítico para la consolidación del nuevo poder Trastámara, a comienzos de 1371 se iniciaron las negociaciones que, con la mediación del legado pontificio Agapito de Colonna, ${ }^{25}$ culminarían en la conclusión de la paz luso-castellana de Alcoutim, firmada a finales de marzo y ratificada por ambos monarcas dentro del mismo año. Sin embargo, la apertura de un frente inglés a comienzos de 1372, asociado a la pretensión de Juan de Gante, duque de Lancáster, al trono castellano, vino a enrarecer las relaciones lusitanoportuguesas, desde el momento en que el rey Fernando I, prestando oídos a las proposiciones inglesas, autorizó las conversaciones sobre una eventual cobertura portuguesa del intento del Lancáster, desde marzo de $1372 .^{26}$

En este respecto, podemos destacar lo bien y puntualmente informado que estaba Gregorio XI, pues ya en abril, como hemos visto, rectificando el curso de los acontecimientos, devolvió a Enrique II los embajadores que éste había designado para ocuparse de la paz con Navarra y Aragón, y anunció la legación de Guido de Boulogne, con plenos poderes, para tratar el asunto de la paz con Portugal, que así volvía a situar en el centro del tapete, cuando en verdad, oficialmente, ese frente debería considerarse cerrado desde la conclusión, un año antes, de la paz de Alcoutim. El hecho de que el pontífice confiara a su mejor diplomático la misión de mediar entre los reyes de Castilla y Portugal, en un momento en que ambos países no se encontraban formalmente en guerra, indica la seriedad de la amenaza que ya en la primavera de 1372 se dejaba sentir en ambientes diplomáticos, sobre la posibilidad de una ofensiva angloportuguesa concertada contra el trono de Enrique II.

Después de indicar claramente su interés en impulsar la causa de la paz entre Castilla y Portugal, Gregorio XI procedió a la rutinaria presentación formal del cardenal legado ante Enrique II, otros miembros de su familia, y algunas de las personalidades que en la Curia pontificia se estimaba especialmente bien situadas para influir cerca del monarca castellano con sus consejos (el obispo de Palencia, y los maestres de las órdenes militares de Santiago, Calatrava y Alcántara). Dicha encomendación de los servicios de Guido de Boulogne tuvo lugar, a buen seguro coincidiendo aproximadamente con el momento en que el legado entraba en España, el 26 de mayo

25 Entonces obispo de Brescia (1369-1371: Eubel, C. 1913: 147); más tarde, de Lisboa (1371-1379: ibidem: 507).

26 Sobre estos acontecimientos: Russell, P. E. 1955. The English Intervention in Spain and Portugal in the Time of Edward III and Richard II. Oxford: Universidad. Suárez Fernández, L. 1956. "Política internacional de Enrique II". Hispania 62: 16-129. Díaz Martín, L. V. 1988. "Los inicios de la política internacional de Castilla (1360-1410)", en: A. Rucquoi (coord.), Realidad e imágenes del poder. España a fines de la Edad Media: 57-83. Valladolid: Ámbito. Valdeón Baruque, J. 1996. Enrique II. 1369-1379: 98-113 y 137-144. Palencia: Diputación Provincial. de 1372: un manojo de bulas con esa fecha, todas redactadas sobre un mismo formulario pero dirigidas separadamente a los destinatarios arriba citados, dan cuenta de ello. ${ }^{27}$

Inmediatamente, el 31 del mismo mes, la cancillería pontificia expidió otra remesa de bulas análoga, conteniendo esta vez la presentación del legado y su misión ante el rey Fernando de Portugal y sus consejeros (entre los que se incluye a Fernando de Castro, al conde de Barcelos, y al prior del Hospital en Portugal). Aprovechando la ocasión, el papa hace enviar otra carta a Enrique II, con la misma fecha y sobre el mismo modelo de la dirigida al rey portugués (y acompañada de otras misivas similares exhortando a otros notables castellanos, como el arzobispo de Toledo y Pedro Fernández de Velasco). ${ }^{28}$

Hechas las presentaciones de rigor y encomendada la misión del legado a la benevolencia de ambas partes interesadas, se inició un proceso de mediación difícil y de momento infructuoso, ${ }^{29}$ pues la tensión entre las dos cortes no cedió en la segunda mitad del año 1372, al término del cual tuvo lugar la invasión castellana en tierras portuguesas. Alarmado por el cariz de los acontecimientos, y deseando detener la escalada del conflicto, el papa quiso persuadir a Enrique II de desembarazarse de sus primeras conquistas en suelo portugués, y el 4 de diciembre instó al monarca castellano a devolver la plaza fronteriza de Miranda de Duero al rey de Portugal, adjuntando a esta bula otra dirigida al cardenal legado para que intercediera por esta devolución. ${ }^{30}$ Según

27 Todas en ASV, Reg. Vat. 268, fols. 145v-146r. Véase la dirigida a Enrique II en el no. 2 de nuestro apéndice.

28 ASV, Reg. Vat. 268, fols. 146v-147v.

29 Tal vez estaban relacionadas con el negocio de esta paz las manifestaciones que el pontífice encargó al cardenal legado hacer a Enrique II, como se acredita por una bula dada el 17 de octubre de 1372, en Aviñón (ASV, Reg. Vat. 268, fol. 193v.): “Carissimo in Christo filio Henrico, Regi Castelle et Legionis illustri, salutem et cetera. Serenitatem regiam, quam in adimplendis uotis nostris promptam semper inuenimus et paratam, rogamus et hortamur in Domino, illam attentius deprecantes et pro speciali munere postulantes, quatenus, pro nostra et apostolice sedis reuerentia, super certis cordi nostro feruenter insidentibus, que uenerabili fratri nostro Guidoni, episcopo Portuense, apostolice sedis legato scripsimus, ipsi legato plenam fidem adhibere, et ad illa que idem legatus pro parte nostra requiret, condescendere sinceritas tua uelit. Benedicat te Deus, et dirigat facta tua. Datum Auinione, xvi kalendas nouembris, anno secundo."

30 1372, diciembre 4, Aviñón. Gregorio XI pide a Enrique II de Castilla que devuelva al rey de Portugal la villa de Miranda (ASV, Reg. Vat. 268, fols. 219r-219v): "Carissimo in Christo filio Henrico, Regi Castelle et Legionis illustri, salutem et cetera. Sincera deuotio quam ad nos et Romanam ecclesiam te habere agnoscimus, spem uigetur cordi nostro, quod exhortationes nostras tibi directas prosecutione laudabili adimplebis. Sane nuper, ex relatione quorundam, percepimus quod nonnulle gentes tue, post pacem inter te et carissimum in Christo filium nostrum Fernandum Regem Portugallie illustrem dudum factam, castrum et uillam de Miranda, in regno Portugallie consistentiam, [129v] et ad ipsum regem Portugalie pertinentia nouiter occuparunt et detinent occupata. Cum autem, fili carissime, in uotis geramus huius pacem inter te et dictum regem Portugallie illibatam seruari, et ad id libenter impendamus studia et labores, regalem excellentiam rogamus et hortamur in Domino, illam attentius deprecantes, quatenus pro nostra et apostolice sedis reuerentia, ac etiam tue salutis et honoris intuitu, huius castrum et uillam prefato regi Portugalie, uel alteri que ad hoc duxerit deputandum, plene et libere restitui facias et in pace dimmitti, ac predictam pacem obserues et per tuos subditos obseruari facias atque mandes: sic preces nostras, prout confidimus, impleturus, quod sinceritatem tuam possimus dignis in Domino laudibus merito commendare. Datum Auinione, 
el conocido testimonio del cronista López de Ayala sobre la invasión castellana, ésta se lanzó desde Zamora y Enrique II entró en Portugal "mediado el mes de diciembre"; ${ }^{31}$ el interés pontificio por la devolución de Miranda a Portugal indica que cuando menos una parte de las operaciones militares castellanas había comenzado antes de esa fecha, y de hecho, el cronista portugués Fernâo Lopes data esta entrada de Enrique II en Portugal a mediados de septiembre. ${ }^{32}$

El éxito de la invasión castellana de Portugal precipitó los acontecimientos. Decidido a interponerse entre los contendientes y procurar un rápido fin al conflicto, el cardenal de Boulogne ignoró la invitación de Enrique II de que aguardara en Guadalajara (donde nos consta que estaba el 15 de diciembre $)^{33}$ al término de las operaciones para entrevistarse con él; pasó a Ciudad Rodrigo, y de allí entró en Portugal, donde se entrevistó con Fernando I antes de ver al monarca castellano. Como es sabido, las arduas negociaciones, en las que el cardenal legado representó un papel clave, no alcanzarían su fruto -el tratado de Santarem- hasta marzo de 1373. En el ínterin, el papa no dejó de exhortar a las partes interesadas, y al mismo cardenal legado, a que se aplicaran muy de veras en lograr la paz. En la reiteración de las bulas expedidas por la cancillería pontificia en esta razón puede percibirse un matiz de impaciencia por unas negociaciones que se prolongaban demasiado: del 26 de enero de 1373 datan sendas bulas exhortando a la paz a los monarcas castellano y portugués, y otra pidiendo al cardenal de Boulogne que se entrevistase con ambos para poner definitivo fin al conflicto; ${ }^{34}$ apenas una semana y media más tarde, el 6 de febrero, el papa remite otra remesa de bulas, instando a ambos soberanos a concluir la paz, así como solicitando un esfuerzo especial al cardenal legado, y la intercesión ante su regio esposo de la reina castellana Juana Manuel. ${ }^{35}$

Concretamente, uno de los argumentos que Gregorio XI propone a los reyes se relaciona con el compromiso de paz previamente alcanzado, con intervención del legado Agapito de Colonna, en 1371: de acuerdo con la paz de Alcoutim, recuerda el pontífice, ninguna de las partes estaba autorizada

ii nonas decembris, anno secundo." Véase el texto de la bula del mismo día dirigida al cardenal de Boulogne, en el no. 6 de nuestro apéndice documental.

31 López de Ayala, P. Crónica de Enrique II: año 7 (1372), cap. 5.

32 Lopes, F. Crónica do senhor rei Dom Fernando: cap. 71.

33 Pues en dicho lugar y fecha expidió el cardenal legado su autorización para el traslado de la comunidad clarisa de Alcocer: cfr. Martín Prieto, P. 2007. "Sobre la promoción regia de la orden franciscana en la Corona de Castilla durante el primer reinado Trastámara" Hispania Sacra 119: 76-77. Vide infra.

${ }_{34}$ 1373, enero 26, Aviñón: Gregorio XI exhorta a Enrique II de Castilla a hacer la paz con Portugal, y le insta a atender las gestiones del cardenal legado Guido de Boulogne (ASV, Reg. Vat. 269, fol. 120r: el texto, en el no. 7 de nuestro apéndice); análogamente, a Fernando I de Portugal (ASV, Reg. Vat. 269, fol. 120r); el pontífice encomienda la tarea de lograr la paz al legado Guido (ASV, Reg. Vat. 269, fol. 120v).

35 1373, febrero 6, Aviñón: Gregorio XI insta a Enrique II de Castilla a concluir la paz con Portugal, accediendo a los buenos oficios de cardenal legado Guido de Boulogne (ASV, Reg. Vat. 269, fol. 7v); análogamente, al rey Fernando de Portugal (ASV, Reg. Vat. 269, fol. 8r); el pontífice pide asimismo a la reina Juana Manuel de Castilla que interceda ante su esposo por la paz con Portugal (ASV, Reg. Vat. 269, fol. 8r), y al cardenal de Boulogne que trabaje para lograr dicha paz (ASV, Reg. Vat. 269, fols. 8r-8v). a reemprender las hostilidades sin previamente comunicar sus motivos a la Santa Sede, y esta precaución había saltado por los aires, evidentemente, con los recientes movimientos de guerra abierta desencadenados en diciembre de 1372:

"quanuis tu [Enrique II] et carissimus in Christo filius noster Fernandus, Rex Portugalie illustris, super guerris et discordiis inter uos -humani generis inimico procurante- dudum exortis, uenerabili fratre nostro Agapito, Ulixbonense, tunc Brixiense episcopo mediante, pacem feceristis, ita quod unus alteri guerram mouere, nisi prius nobis hoc significaret, non deberet siue posset, premissaque firmaueritis propriis iuramentis, prout in capitulis dicte pacis per prefatum episcopum nobis prenotatis plenius continetur, tu tamen et idem rex Portugalie nouam guerram incepistis, uos et subditos ac amicos uestros maximis periculis exponendo". ${ }^{36}$

Finalmente, fue la derrota militar la que persuadió a Fernando de Portugal a firmar la paz con Castilla. Es conocido el protagonismo que en estas negociaciones y en su feliz término le cupo al cardenal legado: el tratado de Santarem, firmado por Fernando I en dicha ciudad el 19 de marzo, el 22 por Enrique II en Lisboa, y ratificado solemnemente el 7 de abril en la célebre entrevista de las tres barcas sobre el Tajo $^{37}$ (significativa representación de la dignidad del legado a latere, émulo de la misma persona del papa, equiparado por la puesta en escena, diseñada por el mismo Guido de Boulogne, con cada uno de los reyes firmantes), se redactó en la cancillería de legación del cardenal, con la forma de un testimonio que él, en primera persona, daba de los capítulos sujetos a compromiso y juramento de las partes firmantes. ${ }^{38}$ Dicho tratado constituye un triunfo de la política del Trastámara, pero también un éxito personal y político del cardenal Guido, que con él podía considerar cumplida una parte principal de su misión (de hecho, como vimos, el detonante inmediato de ella).

\section{LA PAZ CON NAVARRA}

Concluida con éxito la misión del legado en lo tocante a la paz luso-castellana, a Enrique II le quedaban abiertos aún sendos frentes en sus tirantes relaciones con Navarra y Aragón, reinos con los que todavía no se hallaba formalmente en paz, y que constituían otros tantos obstáculos para la consolidación de su reinado. Como en tantos otros puntos, se alineaban en este caso los intereses de la Castilla Trastámara con los de Francia y el Papado de Aviñón; Enrique II deseaba cerrar cuanto antes el contencioso con Navarra, que desde el final del reinado de Pedro I retenía ocupadas algunas villas castellanas fronterizas (señaladamente, Vitoria y Logroño), y tras la conclusión favorable de la paz con Portugal, el cardenal de Boulogne podía concentrar su atención en mediar para la paz de Castilla con sus vecinos del noreste.

36 ASV, Reg. Vat. 269, fol. 120r: apéndice documental, no. 7.

37 López de Ayala, P. Crónica de Enrique II: año 8 (1373), caps. 6 y 7. Lopes, F. Crónica do senhor rei Dom Fernando: caps. 71-73.

38 Publican sendas copias del tratado: Russell, P. E. 1951. "Fernâo Lopes e o tratado de Santarém". Revista Portuguesa de História 5: 455473; Suárez Fernández, L. 1956: 64-77. 
Espoleado por la relativa facilidad con que la solución militar había logrado torcer la voluntad de Fernando de Portugal para inclinarle a la paz, Enrique II, nada más regresar de aquella campaña emprendió otra, de carácter intimidatorio, sobre la frontera navarro-castellana, sentando su real en Santo Domingo de la Calzada. La maniobra surtió efecto, y las negociaciones se desarrollaron en los meses de junio y julio de 1373, interviniendo en ellas el obispo Pedro Tenorio por la parte castellana, y Ramiro de Arellano y Sancho López de Uriz por la parte navarra, todos bajo la supervisión del cardenal legado Guido de Boulogne. El fruto de estas negociaciones fue la paz de San Vicente, firmada el 4 de agosto. ${ }^{39}$ El 22 del mismo mes, Gregorio XI envió sus felicitaciones por la paz a ambos monarcas; en la bula destinada a Enrique II, el papa, al tiempo que le exhortaba a perseverar en esta paz con Navarra, intimó al monarca castellano a emplearse ahora a fondo para concluir la paz con Aragón, cuya negociación, como en seguida veremos, ya se hallaba iniciada, y en ella desempeñaba también un papel eminente el cardenal de Boulogne. ${ }^{40}$

\section{LA PAZ CON ARAGÓN}

Al mismo tiempo que, concluida con éxito la paz castellano-portuguesa, daban comienzo bajo los auspicios del cardenal legado las negociaciones entre Castilla y Navarra, se intentaba asimismo lograr la paz entre Castilla y Aragón, si bien en este último caso las negociaciones estaban mucho menos avanzadas, o las posiciones de partida más enconadas, pues lo cierto es que Guido de Boulogne no pudo ver en vida el fruto de sus esfuerzos. Desde la conclusión de la llamada guerra de los dos Pedros, Pedro IV de Aragón había venido manteniendo una reivindicación sobre ciertas plazas castellanas fronterizas con sus reinos, y en un primer momento, en virtud de los acuerdos por él alcanzados con el Trastámara, aspiraba incluso a la integración en la Corona de Aragón del reino de Murcia. A comienzos de 1372, ambos poderes alcanzaron un provisional modus vivendi, de cordialidad un tanto precaria, por la paz de Alcañiz: apenas una tregua, pero que permitió a Enrique II proseguir su consolidación en el trono castellano y, por un tiempo, ocuparse de otros problemas.

Sin embargo, las relaciones castellano-aragonesas aún estaban presididas por el cálculo y el recelo. Sin duda, las paces de Santarem y San Vicente habían reforzado considerablemente la posición de Enrique II, pero éste aún tenía algo que temer de los movimientos del duque de Lancáster, pretendiente al trono de Castilla con el apoyo de un importante sector del petrismo (o legitimismo). De hecho, en el otoño de 1373, Pedro IV recibió una embajada por la que el de Gante le prometía ayuda inglesa para conquistar las plazas castellanas fronterizas, incluido el reino de Murcia, si el monarca aragonés apoyaba militarmente la proyectada entrada del duque en Castilla. En enero de 1374,

\footnotetext{
39 Valdeón Baruque, J. 1996: 145.

40 Véase el texto de estas bulas en los nos. 10 y 11 de nuestro apéndice. Los dos últimos párrafos de la bula dirigida a Enrique II se hallan publicados en Raynaldi, O. 1880. Annales ecclesiastici, t. 26 (1356-1396): 230. París: ex Typis Consociationis Sancti Pauli.
}

desde Burdeos, Lancáster realizó un ofrecimiento diferente al Ceremonioso: ayuda inglesa a las armas aragonesas en Cerdeña, a cambio del apoyo militar de Aragón a la invasión inglesa de Castilla. Finalmente, en la primavera de 1374 Juan de Gante regresó a Inglaterra, y su proyectada invasión de Castilla quedó para mejor ocasión. ${ }^{41}$ En este desistimiento influyeron varios motivos: ciertamente, la irresolución del monarca aragonés, que evitaba dar una respuesta inequívoca a los avances del Lancáster, por prudencia o temor hacia una Castilla reforzada; pero también la vigilancia o movilización disuasoria de Enrique $\mathrm{II}^{42}$ y probablemente asimismo la mediación de la Curia pontificia, iniciada por el cardenal de Boulogne.

En cuanto a ésta, las gestiones diplomáticas del cardenal legado venían fundadas en la necesidad de reformar o reforzar la paz previa de Alcañiz, para que adquiriera mayor seguridad y consistencia. La primera bula de Gregorio XI en esta razón de la que tenemos noticia data del 21 de abril de 1373: en ella, el pontífice insta a Pedro IV a reformar la paz con Castilla ("ad pacem reformandam [...] cum dicto rege [Enrique II] te commitas"), y para ello le encomienda los servicios del cardenal legado Guido, a quien presenta formalmente, y del archidiácono de Lérida Bernardo de Oliva, que a la sazón era hombre de confianza del Ceremonioso, representante suyo ante la Curia pontificia:

"Bernardo de Oliuis, archidiacono llerdense, latori presentium, qui tui honoris et commodi feruidus zelator, et in Romana curia procurator tuus existit, que propterea ad te exspeciali confidentia destinamus"

Ahora era destinado por el papa con un mensaje especial para el rey aragonés, relacionado sin duda con la consolidación de la paz entre Castilla y Aragón. ${ }^{43}$

Como sabemos, Guido de Boulogne estuvo principalmente ocupado, hasta comienzos de agosto de dicho año de 1373 , en la conclusión de la paz navarro-castellana, que en la referida fecha logró concertar con éxito. Es a partir de este momento cuando el cardenal legado puede concentrar sus energías en el negocio de la paz castellano-aragonesa, y de hecho, cuando el 22 de agosto el papa dirige sus felicitaciones a Enrique II por la reciente paz con Navarra, le insta a asegurarla también con Aragón, para lo cual le remite a los buenos oficios de su legado el cardenal de Boulogne. ${ }^{44}$ Sin embargo, el cardenal Guido no pudo llevar a término su misión, pues falleció en Caspe, el 27 de noviembre de $1373 .{ }^{45}$ Decidido a llevar adelante la misión, aprovechando en lo posible las gestiones que el desaparecido legado hubiera encauzado hasta entonces, el papa decidió confiar la continuidad de la mediación a dos de los compañeros del difunto cardenal, llegados con él a España como miebros de su familia: los obispos Guérin de Chartres ${ }^{46}$ y Oliverio

41 Valdeón Baruque, J. 1996: 146-149.

42 López de Ayala, P. Crónica de Enrique II: año 9 (1374), caps. 1 y 3.

43 El texto, en el no. 9 de nuestro apéndice.

44 Véase el último párrafo del doc. no. 11, en nuestro apéndice.

45 Jugie, P. 1986 [2]: 88.

46 Jugie, P. 1991: 280-281 y notas 52, 57, identifica a este obispo con Guérin d'Arcis (Garinus de Arceyo), canciller del cardenal durante su segunda legación en España. En Eubel, C. 1913: 167, figura Garinus 
de Recanati, ${ }^{47}$ a quienes el 9 de diciembre presenta formalmente, como nuncios de la Santa Sede encargados de proseguir el negocio de la paz iniciado por el legado, ante los monarcas interesados, Pedro IV y Enrique II, ${ }^{48}$ al tiempo que confiaba al obispo de Lérida la misión de dirigir a estos nuncios y supervisar sus gestiones ("prefatos episcopos dirigens in agendis")..$^{49}$ En la misma fecha, el papa dirigió otra bula a los interesados, ${ }^{50}$ en la que les solicitó información especial sobre el punto en que las negociaciones de paz entre Castilla y Aragón habían quedado a la muerte del cardenal legado:

"nosque de tractatu dicte pacis et qualiter negotium se liceat non sumus aliquatenus informati, fraternitatem uestram hortamur [...], quatenus qualiter negotium et tractatus dicte pacis nobis quantocius rescribere non tardetis"

Al tiempo que les instaba a trabajar para concluirlas satisfactoriamente. En los términos en los que estas misivas quedan redactadas, bien que expresado tras el acostumbrado formulismo de la cancillería pontificia ("quod nobis summe displicet"), se trasluce la decepción de Gregorio XI por la pérdida de su primer diplomático Guido de Boulogne, y por la circunstancia de que esta desaparición hubiera truncado en flor las gestiones de la paz entre Castilla y Aragón.

Finalmente, la paz entre Castilla y Aragón no quedaría definitivamente sellada hasta abril de 1375 (tratado de Almazán), ${ }^{51}$ sin que en lo sucesivo, según parece, las gestiones realizadas por los compañeros del cardenal de Boulogne, los nuncios obispos de Chartres y Recanati, hubieran sido decisivas para ello. Sobre la muerte del cardenal Guido corrió en su día la voz de que Carlos II de Navarra lo había hecho envenenar, y de hecho este rumor-quizás no carente de fundamento ${ }^{52}$ - tuvo la fuerza suficiente para que llegara a oídos de la Curia pontificia, pues el mismo Gregorio XI hubo de escribir al rey navarro para reasegurarlo en la confianza del Pontificado, habiendo elegido creer en sus protestas de inocencia. $^{53}$

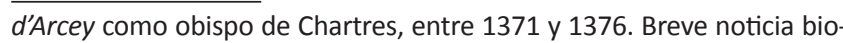
gráfica en: Baudrillart, A. 1938: cols. 1526-1527 ("Guérin d'Arcey").

47 Oliverio de Verona, obispo de Recanati (1369-1374): Eubel, C. 1913: 410. En la bula de 9 de diciembre de 1373 (ASV, Reg. Vat. 269, fol. 241v), doc. no. 12 de nuestro apéndice, se lo llama Oliverio de Braga (tal vez tuvo en dicha diócesis, de la que no fue obispo, algún beneficio eclesiástico, o quizás era natural de Braga, aunque en Eubel se lo llame "de Verona").

48 1373, diciembre 9, Aviñón. Gregorio XI presenta a Pedro IV de Aragón a los nuncios que, tras la muerte del legado Guido de Boulogne, proseguirán la negociación de la paz con Castilla: ASV, Reg. Vat. 269, fol. $241 v$ (doc. no. 12 de nuestro apéndice). Análogamente, y con la misma fecha, presentación a Enrique II de Castilla: ASV, Reg. Vat. 269, fol. 241v.

${ }_{49} 1373$, diciembre 9, Aviñón. Gregorio XI presenta al obispo de Lérida a los nuncios Guérin, obispo de Chartres, y Oliverio, obispo de Recanati, y le ruega que los dirija en la prosecución de la misión de paz entre Castilla y Aragón: ASV, Reg. Vat. 269, fols. 241v-242r.

50 ASV, Reg. Vat. 269, fol. 242 r (el texto, en el no. 13 de nuestro apéndice).

51 Valdeón Baruque, J. 1996: 152-153.

52 Jugie, P. 1986 [2]: 88, da crédito a esta acusación: "sans doute empoisonné", escribe.

53 Noticia de este rumor sobre la muerte por veneno de Guido de Boulogne y la bula de Gregorio XI descartando las sospechas de la Santa Sede sobre Carlos II de Navarra, en Raynaldi, O. 1880: 230.

\section{OTROS ASUNTOS}

Pero al lado del negocio principal de la legación -la paz entre Castilla y sus vecinos ibéricos-, el cardenal de Boulogne, durante esta su segunda estadía en España, tuvo ocasión de ocuparse de otros variados asuntos, que escogemos tratar ahora por separado. Se trata, de un lado, de misiones encomendadas por la Curia pontificia, relacionadas con asuntos pendientes, arrastrados de otras legaciones y nunciaturas anteriores, o sobrevenidos precisamente durante el tiempo que el cardenal de Boulogne estuvo en España; de otro, una variedad de gestiones, menores y mayores, que le fueron solicitadas por diversas instancias del clero peninsular, habitualmente aprovechando el paso del cardenal por las distintas localidades.

Un viejo asunto, que nunca parecía acabar de resolverse, y que en el pasado ya había servido de justificación para el envío de nuncios y legados, era el interés que el Pontificado tenía por saldar definitivamente el destino de los bienes incautados en Castilla a la orden templaria, al tiempo de su disolución. ${ }^{54}$ En los tiempos del rey Pedro, cuando las relaciones entre la corona castellana y el Papado eran especialmente tirantes (debido, en buena medida, al alineamiento de los pontífices de Aviñón con los intereses diplomáticos de la corona francesa), la suerte de los bienes de los templarios había sido utilizada como excusa para enviar legados a Castilla; muy probablemente, los pontífices no se hacían demasiadas ilusiones sobre el éxito de las gestiones para la devolución de los bienes incautados al Temple, pero seguían utilizando el asunto como una pantalla o cobertura, de índole escasamente polémica, en legaciones cuya verdadera agenda operativa y central residía en otras cuestiones diplomáticas del más alto nivel. Así, fue interesarse por la devolución de los bienes que fueron del Temple la misión que formalmente motivó el envío como legado del obispo de Senez en 1354 a Castilla, ${ }^{55}$ y asimismo el cardenal Guillermo de la Jugie planteó el asunto durante el tiempo de su legación (1355-1358). ${ }^{56}$

En cualquier caso, con independencia del resultado efectivo que pudiera tener la reivindicación, la diplomacia pontificia nunca retiró el tema de la agenda de sus embajadas, y también el cardenal Guido de Boulogne se ocupó brevemente del asunto. Tenemos noticia de tres bulas, datadas las tres el 14 de noviembre de 1372, mediante las cuales Gregorio XI parecía decidido a impulsar la resolución del contencioso. En la primera, ${ }^{57}$ el pontífice deniega la petición del monarca aragonés Pedro IV para que las encomiendas y casas de las órdenes de Santiago y Calatrava radicadas en suelo de la Corona de Aragón se separasen de la autoridad de sus respectivos maestres castellanos (como se hizo con las portuguesas), y acto seguido, trayendo a colación

54 De 1319 (marzo 14), databa la decisión de Juan XXII disponiendo que los bienes castellanos del Temple pasaran a la orden hospitalaria: Archivo Histórico Nacional (Madrid), Órdenes Militares, San Juan de Jerusalén, carpeta 569, doc. no. 31.

55 Zunzunegui Aramburu, J. 1970. Bulas y cartas secretas de Inocencio VI: 58-61. Roma: Instituto Español de Historia Eclesiástica.

56 Zunzunegui Aramburu, J. 1964: 143.

57 El texto, en el no. 5 de nuestro apéndice. 
el asunto de los bienes incautados al Temple por la corona castellana, propone la solución imaginativa de que precisamente de estos intereses en suelo aragonés, sujetos a los maestres castellanos de Santiago y Calatrava, se hiciera un priorato de la orden del Hospital, sucesora de la templaria; 58 a tal efecto, el papa encarga al cardenal de Boulogne que realice una investigación dirigida a establecer el valor actualizado de los bienes que en su día le fueron tomados al Temple en Castilla, y le exhorta a que indague sutilmente sobre la disposición del rey de Castilla a adoptar esta solución en general, como medio de resolver el largo contencioso, traspasando lugares y bienes castellanos de Santiago y Calatrava al Hospital. En la segunda bula, el papa pide al cardenal legado que inste al rey castellano a devolver lo en su día incautado a la orden templaria, ${ }^{59}$ y en la tercera, el mismo Enrique II es objeto directamente de dicha reclamación. ${ }^{60}$ No nos consta que el cardenal de Boulogne volviera a ocuparse del asunto durante el tiempo de su legación, si bien sabemos que Gregorio XI retomaría el negocio más adelante en su pontificado, dirigiendo nuevas proposiciones a Enrique II en el mismo sentido, al parecer sin efecto. ${ }^{61}$

Otro asunto diferente al que el cardenal de Boulogne tuvo que dedicar alguna atención lateral atañía a la misión que, coincidiendo con el tiempo de su legación, la Curia pontificia encomendó al canónigo narbonense Jacobo de Sirano, enviado a Castilla y Portugal como nuncio colector. ${ }^{62}$ En un racimo de bulas expedidas el 9 de enero de 1373, al tiempo que le otorgaba los correspondientes poderes, ${ }^{63}$ el papa encomendó la misión de este colector al propio cardenal legado, ${ }^{64}$ así como a otras varias autoridades religiosas de Castilla. ${ }^{65}$ Realmente, no existe en este respecto superposición o solapamiento entre las facultades de uno y otro,

58 En Castilla eran precisamente esas órdenes las máximas detentadoras, por concesión regia, de bienes que en su día fueron del Temple: Estepa Diéz, C. 1975. "La disolución de la orden del Temple en Castilla y León". Cuadernos de Historia. Anexos de la revista Hispania 6: 180-182.

59 1372, noviembre 14, Aviñón. Gregorio XI encarga a su legado en España, el cardenal Guido de Boulogne, que exhorte a Enrique II de Castilla a devolver los bienes que fueron de la orden templaria en Castilla: ASV, Reg. Vat. 268, fol. 206r.

60 1372, noviembre 14, Aviñón. Gregorio XI ruega a Enrique II de Castilla que restituya al Hospital los bienes que fueron de la orden templaria en sus reinos: ASV, Reg. Vat. 268, fols. 242v-243r.

61 Así pues, esta propuesta pontificia de vincular la restitución al Hospital de los bienes del Temple con el asunto de los bienes aragoneses de las órdenes de Santiago y Alcántara no es una "novedad" en 1375, como se venía afirmando: Barquero Goñi, C. 1993. "El conflicto por los bienes templarios en Castilla y la Orden de San Juan". En la España medieval 16: 52.

62 Sobre la misión de este colector, Nieto Soria, J. M. 1993: 69.

63 1373, enero 9, Aviñón: Gregorio XI da poderes por un año a su nuncio Jacobo de Sirano, como colector en Castilla y Portugal (ASV, Reg. Vat. 265, fols. 93r-93v), así como para proceder contra quienes lo injurien (ASV, Reg. Vat. 265, fol. 98r), le faculta para cobrar 50.000 florines pendientes de la colectoría del nuncio anterior Bertrando, cardenal de San Marcelo, por el reino de Castilla (ASV, Reg. Vat. 265, fol. 93v), y otros 20.000 florines de la misma colectoría anterior, por el reino de Portugal (ASV, Reg. Vat. 265, fol. 98r).

64 1373, enero 9, Aviñón. Gregorio XI encomienda a su legado en España el cardenal Guido de Boulogne la misión de su nuncio y colector Jacobo de Sirano: ASV, Reg. Vat. 269, fols. 113r-113v.

65 1373, enero 9, Aviñón. En sendas bulas, Gregorio XI encomienda la misión del colector Sirano a los arzobispos de Santiago de Compostela, Toledo y Sevilla: ASV, Reg. Vat. 269, fol. 113v. pues en tanto al colector se le confiaba una misión ordinaria de índole fiscal, el legado continuaba consagrado al despacho de negocios diplomáticos al más alto nivel (digamos político). En este punto, al cardenal de Boulogne sólo se le pidió que patrocinara y dirigiera las gestiones del colector desde arriba, como una suerte de supervisión de su obra:

\begin{abstract}
"fraternitatem tuam rogamus et hortamur attente [...] quatenus [...], dictum nuncium habens propensius comendatum, sic eum dirigas in agendis quod ipse, sinceritatis tue fultus presidio, negocia per nos ei commissa bene peragere ualeat".66
\end{abstract}

Las cuestiones, más o menos ordinarias, relativas a la disciplina del clero hispano, ocuparon asimismo una parte de la atención del legado Guido de Boulogne: concretamente, consta en abril de 1373 el encargo pontificio de que procediera contra ciertos clérigos castellanos rebeldes o conspiradores, que al parecer tramaban la subversión contra Enrique II, sin que sepamos precisar la identidad de los tales o el carácter de sus actividades, que parecen haber tenido un cariz marcadamente político (tal vez petristas coordinados con algunos movimientos de los enemigos exteriores del Trastámara, pues se dice que eran portadores de embajadas):

"Nuper ad nostrum -non sine mentis turbationeperuenit auditum quod nonnulle persone ecclesiastice, etiam religiose, quique etiam sub diuinis habitibus per regna Castelle et Legionis discurrentes, nonnullos tractatus facere, et diuersas ambaxiatas portare, et conplura alia peragere contra prosperum statum et tranquillum carissimi in Christo filii nostri Henrici, regis Castelle et Legionis illustris, et in subuersionem regnorum predictorum presumunt". ${ }^{67}$

También ignoramos el curso que más tarde siguió el asunto, y la suerte de estos clérigos subversivos. Otro problema, mucho menos sorprendente en el seno de la Iglesia hispana, ${ }^{68}$ atañía al comportamiento poco ejemplar de los clérigos concubinarios o amancebados: para corregir este vicio, envió Gregorio XI a la península a dos nuncios, el abad tolosano Juan y el decano de la iglesia de Angulema Arnaldo, cuya misión se menciona en términos de encomio en la bula de 22 de agosto de 1373 ya citada, ${ }^{69}$ al tiempo que, por otra bula del mismo día, se asignó al cardenal de Boulogne el cometido de ayudarlos y dirigirlos en sus funciones. ${ }^{70}$

En la primavera de 1373 consta que el legado Guido hubo asimismo de ocuparse -siquiera brevemente- de la

66 Véase la bula dirigida a Guido de Boulogne: ASV, Reg. Vat. 269, fols. $113 r-113 v$ (nota 63, supra).

67 Cfr. doc. no. 8 en nuestro apéndice. Asismismo, 1373, abril 16, Aviñón: Gregorio XI instruye a todo el clero hispano contra dichos clérigos conspiradores: ASV, Reg. Vat. 265, fol. 123r.

68 Véase, por ejemplo, el revelador trabajo Arranz Guzmán, A. 2008. "Celibato eclesiástico, barraganas y contestación social en la Castilla bajomedieval". Espacio, tiempo y forma. Serie III: Historia Medieval 21: 13-39.

69 Su texto, en el no. 11 de nuestro apéndice.

70 1373, agosto 22, Villeneuve-lès-Avignon. Gregorio XI encarga a su legado en España el cardenal Guido de Boulogne que dirija a los nuncios enviados para el asunto de los clérigos concubinarios y él se concentre en lograr la paz entre Castilla, Navarra y Aragón: ASV, Reg. Vat. 269 , fol. 204r. 
curiosa reclamación por la sucesión de Vizcaya presentada ante la Curia pontificia por una mujer noble que se decía depositaria de la herencia de los Lara, en perjuicio de los derechos de la reina Juana Manuel al mismo señorío, que a la sazón se consideraba ya definitivamente incorporado a la corona castellana. ${ }^{71}$ En el verano del mismo año, el papa encargó al legado que prestara su mediación para convencer a Pedro IV de Aragón de que concediera salvoconducto a Juan de Heredia para acudir al capítulo general de la orden hospitalaria. ${ }^{72}$ En ambos casos, las gestiones encomendadas al legado parecían de menor enjundia, limitándose, con toda probabilidad, a realizar intervenciones accesorias a las cartas que el Pontificado envió directamente a los interesados (los monarcas castellano y aragonés, de quienes se esperaba una actitud favorable a las demandas pontificias). Sobre los asuntos de esta índole, cabe suponer que al cardenal de Boulogne no le cupo verdadero protagonismo, pero sencillamente le fueron remitidos como información de la agenda que el Papado desarrollaba por entonces con los reinos ibéricos, y con la esperanza de que la marcha de estos negocios se beneficiara de los buenos oficios del legado.

Junto a estos otros asuntos, que estimamos menores por comparación con los esfuerzos y la atención que dedicó a la causa de la paz entre los reinos ibéricos, el cardenal de Boulogne tuvo asimismo ocasión, durante el tiempo de su segunda legación española, de ocuparse de toda una serie de asuntos sobrevenidos y locales, presentados frecuentemente in situ a su consideración por distintas instituciones y personas eclesiásticas hispanas. Sin duda, la alta representación que el cardenal Guido traía a la península como legado a latere, su propio prestigio como el principal talento diplomático del sacro colegio, y la oportunidad de someter asuntos polémicos al criterio de un árbitro potencialmente imparcial, fueron otros tantos motivos del interés que cabildos o monasterios tuvieron en llevar sus casos ante la pequeña corte itinerante del cardenal de Boulogne.

Fue así que, ya en la primavera de 1372, coincidiendo probablemente con la llegada del cardenal Guido a España, el papa, a instancias del obispo y cabildo de Pamplona, le encargó la resolución del pleito que por entonces dicha sede episcopal mantenía con el monasterio de Montearagón, a cuenta de la jurisdicción sobre cierto número de iglesias navarras y la percepción de rentas decimales. A finales de agosto del mismo año, desde Barcelona, hallamos al cardenal actuando ya como juez árbitro de dicho proceso,

71 1373, mayo 26, Sorgues: Gregorio XI pide a Enrique II de Castilla que restituya el señorío de Vizcaya a cierta Juana Núñez, que dice ser la viuda de su hermano Tello; en la misma fecha, el papa interesa en el asunto a la reina Juana Manuel de Castilla y a su legado en España, el cardenal Guido de Boulogne: ASV, Reg. Vat. 269, fols. 169v-170v. No fue esta la única reclamación por la herencia de los Lara a la que Enrique II hubo de hacer frente en 1373. Cfr. un estudio pormenorizado del problema: Martín Prieto, P. 2013. “El destino de Juana de Lara, y la herencia del señorío de Vizcaya en los albores del periodo Trastámara”. En la España medieval 36: 115-134.

72 1373, agosto 8, Villeneuve-lès-Avignon: Gregorio XI pide a Pedro IV de Aragón que no impidiera a Juan de Heredia asistir al capítulo general de la orden del Hospital, e interesa en el asunto a su legado en España, el cardenal Guido de Boulogne: ASV, Reg. Vat. 269, fol. 70 v. cuando, disponiendo de los argumentos de la sede pampilonense (y de tres sentencias previas favorables a la misma) pide al abad de Montearagón que le exponga sus reivindicaciones al respecto. ${ }^{73}$

Asimismo, sabemos que el cardenal de Boulogne se implicó en Castilla en algunas operaciones de traslado de comunidades religiosas a nuevos complejos monásticos más sólidamente incardinados en el ámbito urbano: así, como legado y en representación del Pontificado concedió el permiso para el traslado de la comunidad clarisa de Alcocer, al norte del obispado de Cuenca, desde su primera sede extramuros a un monasterio nuevo en el interior de dicha villa (en Guadalajara, el 15 de diciembre de 1372), y del convento clariso de Reinoso a Palencia (en Valladolid, el 29 de mayo de 1373). ${ }^{74}$ En ambos casos, a la intervención del cardenal legado se unió decisivamente el impulso prestado por la corona castellana a dichas operaciones de traslado, que probablemente es necesario comprender dentro de una línea política general de restauración religiosa propia del primer reinado Trastámara, y en cualquier caso viene a constituir una interesante ilustración del compromiso del cardenal de Boulogne en este tipo de pequeños y grandes asuntos locales de la Iglesia hispana, a los que durante el tiempo de su legación hubo de dedicar, siquiera de manera subsidiaria, alguna atención.

\section{CONCLUSIÓN}

Por más de un motivo, la segunda legación española del cardenal Guido de Boulogne retiene la atención del historiador: no sólo se trata de una de las cada vez menos raras misiones diplomáticas al más alto nivel con las que el Pontificado venía anudando sus relaciones más y más estrechas con las monarquías hispánicas, y una ocasión más de comprobar la variedad y la profundidad de la agenda que los papas de Aviñón mantuvieron a lo largo del siglo XIV con los reinos ibéricos, sino que además ofrece un cauce privilegiado de aproximación a las complejas negociaciones de la paz entre dichos reinos, en las que como es sabido el Pontificado tuvo un protagonismo bien patente, amén de servir como ilustración de los problemas y cuestiones muy diversos que en la época acababan llegando a oídos de los legados en el curso de sus misiones, cuando por distintas instancias del clero local se les hacía partícipes, o jueces, de asuntos plenamente locales, más o menos enquistados, pero en todo caso de resolución no mecánica, en la que sus buenos oficios tantas veces se revelaban decisivos.

73 1372, mayo 25, Sorgues. Gregorio XI, a petición del obispo y cabildo de Pamplona, encarga a su legado en España el cardenal Guido de Boulogne la resolución del pleito entre dicha sede y el monasterio de Montearagón; 1372, agosto 30, Barcelona. El cardenal Guido de Boulogne cita al abad de Montearagón para que presente los términos de su causa en dicho pleito: Goñi Gaztambide, J. 1965: 352-353 (docs. nos. 1472 y 1474$)$.

74 El texto de ambos documentos, respective, en: Martín Prieto, P. 2007: 76-77, y Castro, M. 1983. Real Monasterio de Santa Clara de Palencia. II. Apéndice documental: 5-6. Palencia, Diputación Provincial. 


\section{FUENTES}

Città del Vaticano, Archivum Secretum Vaticanum (ASV), Registra Vaticana (RegVat): volúmenes nos. 264, 265, 268, 269, 272.

España, Archivo Histórico Nacional (AHN), Órdenes Militares, San Juan de Jerusalén, carpeta 569, doc. no. 31.

\section{BiBLIOGRAFÍA}

Arranz Guzmán, A. 2008. “Celibato eclesiástico, barraganas y contestación social en la Castilla bajomedieval". Espacio, tiempo y forma. Serie III: Historia Medieval 21: 13-39.

Baluze, S. 1693. Vitae Paparum Avenionensium, t. I. París: François Muguet.

Barquero Goñi, C. 1993. "El conflicto por los bienes templarios en Castilla y la Orden de San Juan". En la España medieval 16: 52-71.

Díaz Martín, L. V. 1988. "Los inicios de la política internacional de Castilla (1360-1410)", en: A. Rucquoi (coord.), Realidad e imágenes del poder. España a fines de la Edad Media: 57-83. Valladolid: Ámbito.

Duchesne, F. 1666. Histoire de tous les cardinaux français de naissance, t. II. París: impreso por el autor.

Estepa Diéz, C. 1975. "La disolución de la orden del Temple en Castilla y León". Cuadernos de Historia. Anexos de la revista Hispania 6: 180-182.

Eubel, C. 1913. Hierarchia Catholica, t. I. Münster: ex Typis Librariae Regensbergianae.

Goñi Gaztambide, J. 1965. Catálogo del Archivo Catedral de Pamplona. Tomo I (829-1500). Pamplona: Diputación Foral de Navarra.

Guillemain, B. 1962. La Cour Pontificale d'Avignon (13091376). Étude d'une société. París: Éditions E. de Boccard.

Jugie, P. 1986. Le cardinal Gui de Boulogne (1316-1373): biographie et étude d'une familia cardinalice (tesis inédita para la obtención del Diplôme d'archiviste paléographe en la École Nationale des Chartes, 3 vols. Mecanografiados). París: École Nationale des Chartes.

Jugie, P. 1986 [2]. Positions des thèses soutenues par les élèves de la promotion de 1986: 83-92. París: École Nationale des Chartes.

Jugie, P. 1987. "L'activité diplomatique du cardinal Gui de Boulogne en France au milieu du xIV siècle". Bibliothèque de l'École des Chartes 145: 99-127.

Jugie, P. 1989. "La légation en Hongrie et en Italie du cardinal Gui de Boulogne (1348-1350)". II Santo. Rivista antoniana di storia, dottrina, arte 29: 29-69.
Jugie, P. 1990. "Les familiae cardinalices et leur organisation interne au temps de la papauté d'Avignon: esquisse d'un bilan", en: Le fonctionnement administratif de la Papauté d'Avignon, (Actas de la mesa redonda de la École Française de Rome, Aviñón, enero de 1988): 41-59. Roma: École Française de Rome.

Jugie, P. 1991. "Le vicariat impérial du cardinal Gui de Boulogne à Lucques en 1369-1370". Mélanges de l'École Française de Rome. Moyen Âge, Temps Modernes 103/1: 261-357.

Martín Prieto, P. 2007. "Sobre la promoción regia de la orden franciscana en la Corona de Castilla durante el primer reinado Trastámara". Hispania Sacra 119: 76-77.

Martín Prieto, P. 2013. “El destino de Juana de Lara, y la herencia del señorío de Vizcaya en los albores del periodo Trastámara". En la España medieval 36: 115-134.

Mendi, J. M. 1964. "La primera legación del cardenal Guido de Boulogne a España (1358-1361)". Scriptorium Victoriense 11: 135-224.

Mollat, G. 1912. Les papes d'Avignon (1305-1378). París: Librairie Victor Lecoffre.

Mollat, G. 1938. "Gui de Boulogne”, en A. BAUDRILLART et alii (eds.), Dictionnaire d'Histoire et de Géographie Écclesiastiques, t. X: cols 101-106. París: Letouzey et Ané

Nieto Soria, J. M. 1993. Iglesia y génesis del Estado moderno en Castilla (1369-1480). Madrid: Universidad Complutense.

Raynaldi, O. 1880. Annales ecclesiastici, t. 26 (13561396). París: ex Typis Consociationis Sancti Pauli.

Russell, P. E. 1951. "Fernâo Lopes e o tratado de Santarém". Revista Portuguesa de História 5: 455-473.

Russell, P. E. 1955. The English Intervention in Spain and Portugal in the Time of Edward III and Richard II. Oxford: Universidad.

Suárez Fernández, L. 1956. "Política internacional de Enrique II". Hispania 62: 16-129.

Valdeón Baruque, J. 1996. Enrique II. 1369-1379. Palencia: Diputación Provincial.

Zunzunegui Aramburu, J. 1943. "La legación en España del cardenal Pedro de Luna, 1379-1390". Miscellanea Historiae Pontificiae 7: 83-137.

Zunzunegui Aramburu, J. 1960. "La misión del obispo de Senez al reino de Castilla (1354-1355)". Anthologica Annua 8: $11-42$.

Zunzunegui Aramburu, J. 1964. "La legación del cardenal Guillermo de la Jugie a Castilla y Aragón (1355-1358)". Anthologica Annua 12: 129-156.

Zunzunegui Aramburu, J. 1970. Bulas y cartas secretas de Inocencio VI. Roma: Instituto Español de Historia Eclesiástica. 


\section{APÉNDICE DOCUMENTAL}

1

\section{2, abril 21, Aviñón.}

Gregorio XI participa a Enrique II de Castilla la recepción de sus embajadores el obispo de Coimbra y el jurista Juan Alfonso, enviados para tratar la paz con Aragón y Navarra, pero sin poderes suficientes, y anuncia al rey el envío como legado del cardenal Guido de Boulogne, a quien presenta formalmente, con la misión añadida de afianzar la paz con Portugal.

\section{ASV, Reg.Vat. 268 , fols. $134 v$ y $135 r-135 v$.}

Carissimo in Christo filio Henrico, Regi Castelle et Legionis illustri, salutem et cetera. Venerabilem fratrem nostrum Petrum, episcopum Colimbriensem, et dilectum filium Johannem Alfonsi, utriusque iuris professorem, ambaxiatores tuos pro parte regalis excellentie pro bona concordia inter te ex parte una, et carissimos in Christo filios nostros Petrum, Aragonum, et Carolum, Nauarre, reges illustres, complenda, super qua per partes in nos conpromissum extiterit ad nos destinatos grate recepimus, et que pro parte tua nobis exposuerunt intellectis, sinceritatis et deuotionis tue studium multipliciter commendamus, uerum cum tui et regum predictorum ambaxiatores et nuntii mandata habeant limitata, et cum eis de facili huius negotia, que in se sunt ardua, hic deputati nequeant expediri, nos, pro pacifico statu et transquillo regnorum et terrarum tue dictioni subiectorum, ac reformatione plenaria, et pro celeriori et feliciori expeditione predicte discordie, et etiam pro bona concordia inter te et carissimum in Christo filium nostrum Fernandum Regem Portugallie conseruanda, uenerabilem fratrem nostrum Guidonem, episcopum Portuensem, apostolice sedis legatum, qui uir timoratus et prouidus, nobilitate perspicuus, ac frequenter in arduis etiam in illis partibus conprobatus, clarus scientia, plenusque multis uirtutibus fore dinoscitur, quique etiam tuum commodum et honorem, et tuorum, semper dilexit et diligit, ad partes illas prouidimus destinandum, ac predictos ambaxiatores tuos, quorum industriam et solicitudinem multipliciter commendamus, ad serenitatem tuam remittimus, eam attentius deprecantes, et pro uiscera nomine Dei nostri attentius exhortantes, quatenus diuine propitiationis intuitu, publice utilitatis obtentu, pro nostra quoque interuentione ad bonam concordiam, prout alias super hoc tibi sepius scripsimus, tuum disponas animum, habilites et mentem, ita quod omnipotentem Deum tibi constituas propitium, nosque deuotionis tue promptitudinem dignis in Domino laudibus attollamus. Datum Auinione, xi kalendas maii, anno secundo.

2

\section{2, mayo 26, Sorgues.}

Gregorio XI recomienda la misión de su legado Guido de Boulogne ante Enrique II de Castilla.
ASV, Reg. Vat. 268, fol. $145 \mathrm{v}$.

Carissimo in Christo filio Henrico, Regi Castelle et Legionis illustri, salutem et cetera. Cum uenerabilem fratrem nostrum Guidonem, episcopum Portuensem, apostolice sedis legatum, ad Ispanie, Aragonie et nonnullas alias partes, commisso plene legationis officio, pro bono et pacifico statu partium earundem, et pro certis aliis arduis negociis presentialiter destinemus, serenitatem tuam attente rogamus, quatenus eidem legato, in hiis pro quibus eum mittimus, et que ex parte nostra tibi dicet, adhibeas plenam fidem. Datum apud Pontemsorgie, Auinioensis diocesis, vii kalendas junii, anno secundo.

3

1372, julio 8, Aviñón.

Gregorio XI concede a su legado en España, el cardenal Guido de Boulogne, facultad para dispensar del voto de Santiago a cinco personas de su comitiva.

ASV, Reg.Vat. 268, fol. 165 r.

Venerabili fratri Guidoni, episcopo Portuensi, apostolice sedis legato, salutem et cetera. De circumspectione tua, in arduis sepius comprobata, plurimum in Domino confidentes, dispensandi cum quinque personis tue legationis, quas duxeris eligendas, super uoto Sancti Jacobi per eas emisso, que uotum ipsum commode adimplere non possunt, ac uotum ipsum in alia opera pietatis commutandi, ita tamen quod expensas quas persone ipse in eundo, morando et redeundo, et etiam illud quod pro labore ipsorum reccompensabis, dicte persone ad ecclesiam eiusdem Sancti Jacobi transmittant, fraternitati tue plenam et liberam tenore presentium concedimus facultatem. Datum Auinione, viii idus julii, anno secundo.

\section{4}

1372, agosto 15, Villeneuve-lès-Avignon.

Gregorio XI concede a su legado en España, el cardenal Guido de Boulogne, facultad para dispensar de defecto de nacimiento a cien candidatos a la provisión de beneficios eclesiásticos.

ASV, Reg.Vat. 264, fol. 140r. En Reg. Vat. 272, fol. 20r, el mismo texto, con fecha: 1373, julio 13, Aviñón ("Datum Auinione, iii idus julii, anno tertio").

Venerabili fratri Guidoni, episcopo Portuensi, apostolice sedis legato, salutem et cetera. Cum te ad Castelle et Legionis, Aragonum, Portugallie et Nauarre regna, commisso tibi in eis plene legationis officio, pro certis arduis negociis duxerimus destinandum, nos uolentes aliqua tibi concedere per que personis illarum partium te reddere ualeas gratiosim, fraternitati tue dispensandi cum centum personis illarum partium, de quibus tibi uidebitur, super defectum natalium que patiuntur de presbytero uel religioso, et soluta aut coniugata genitrice, que huius non ostante deffectu, si paterne non fuerint incontinentie septatrices, sed bone conuersationis et uite, aliosque ipsis merita suffragentur, ad 
huius dispensationis gratiam obtinendam, ad omnes ordines promoueri, et earum quemlibet beneficium ecclesiasticum, cum cura uel sine cura, si ei aliud canonice conferatur, obtinere ualeat, plenam concedimus auctoritate presentium facultatem. Datum apud Villamnouam, Auinoniensis diocesis, xviii kalendas septembri, anno secundo.

\section{5}

\section{2, noviembre 14, Aviñón.}

Gregorio XI da instrucciones a su legado en España, el cardenal Guido de Boulogne, sobre el destino de los bienes del Temple incautados por la Corona de Castilla.

\section{ASV, Reg. Vat. 268, fols. 205r-206r.}

Venerabili Guidoni, episcopo Portuensi, apostolice sedis legato, salutem et cetera. Nuper [205v] carissimus in Christo filius noster Petrus, Rex Aragonum illustris, nobis supplicari fecit ut dilectos filios Sancti Jacobi et de Calatraua militiarum, seu domorum preceptores et fratres ac domos ipsas in suis regnis et terris consistentes, ab omni jurisdictione domo et priorate suorum superiorum in regnis Castelle et Legionis consistentium, pro bono et securo statu huius regnorum et terrarum suarum, eximere, prout in casu simili per fratrem reuerendissimum Johannem, papam uicesimum secundum, predecessorem nostrum, in regno Portugallie factum fuisset, de benignitate apostolica dignaremur; nos igitur, qui intentis desideriis affectamus et excitamur, cura procurare soliciter, ut in predictis regnis et terris eiusdem regis Aragonum uigeat transquille beatitudo quietis ne dictus rex quamuis turbationum fluctuationem uexetur, quem desideramus plenis affectibus pacifici status prosperitate letari, timentes quod per hoc status pacificus dicti regis, et etiam carissimi in Christo filii nostri Henrici, Regis Castelle et Legionis illustris, et regnorum ac terrarum ipsorum, perturbari possent, supplicationem huius non duxerimus admittendam, et cum alia uia ab aliquibus nobis dicta esset, uidelicet, quod si de bonis que iidem magistri, preceptores et fratres miliciarum seu domorum Sancti Jacobi et de Calatraua in predictis regnis et terris eiusdem regis Aragonum habere noscuntur pro bonis que dilecti filii magistri et fratres hospitalis Sancti Johannis Jerosolimitani, que quondam Templariorum fuerunt, et que nunc per dictum regem Castelle et Legionis, seu nonnullos eius nobiles, occupata tenentur in regnis Castelle et Legionis, habere dicuntur, pro quorum restitutione facienda eidem regi Castelle et Legionis illustri, prout bene nosti, scribimus, permutatio huius idem fieret transquillitas et utilitas partibus ipsis prouenire, et dicta bona, que ecclesiastici iuri existunt, de manui dicti regis et aliorum laycorum facilius recuperari posse, uerisimiliter crederentur, quidque etiam de predictis bonis in dictis regnis et terris eiusdem regis Aragonum consistentibus unus prioratus honorabilis eiusdem hospitalis Sancti Johannis creari et ordinari posset: uiam ipsam credimus meliorem, ac de circunspectione tua, in arduis sepius conprobata, plurimum in Domino confidentes, fraternitatem tuam hortamur attentius, tibi nichilominus per apostolica scripta mandantes, quatenus de ualore omnium et singulorum bonorum predictorum, tam illorum uidelicet que in dictis regnis Castelle et Legionis dudum Templarii habuerunt et nunc per dictum regem aut alios, ut prefertur, detinentur, quam illorum que Sancti Jacobi et de Calatraua militiarum preceptores et fratres in regnis et domis dicti regis Aragonum habere dicuntur, [206r] per te uel alium seu alios deligenter te informes, et ad id predictorum magistrorum et preceptorum militiarum Sancti Jacobi et de Calatraua consensum requiras, et si huius magistri et fratres aliquid dicere uel oponere uoluerint, quare non sit huius permutatio facienda, illos audias et etiam solicite perscrutari uelis an prefatus rex Castelle et Legionis de permutatione huius contentus esset, et utrum predicta bona que Templariorum fuerunt libentius dictis magistris, preceptoribus et fratribus militiarum Sancti Jacobi et de Calatraua quod prioribus et fratribus dicti hospitalis Sancti Johannis Jerosolimitani restituent, et quicquid super premissis repperitis, et quid etiam eidem circunspectioni tue super hiis uidebitur, per tuas clausas litteras tue sigillo signatas, hanc seriem continentes, nobis quantocius rescribere non omittas, ut tua super hiis informatione instructi, in eis consultius agere ualeam. Datum Auinione, xviii kalendas decembris, anno secundo.

\section{6}

\section{2, diciembre 4, Aviñón.}

Gregorio XI encomienda a su legado en España, el cardenal Guido de Boulogne, que interceda ante Enrique II de Castilla para que éste devuelva a Portugal la villa de Miranda.

\section{ASV, Reg. Vat. 268, fol. 219r.}

Venerabili fratri Guidoni, episcopo Portuensi, apostolice sedis legato, salutem et cetera. Carissimo in Christo filio nostro Henrico, Regis Castelle et Legionis illustri, cuius gentes, ut percepimus, castrum et uillam de Miranda, que sunt regis Portugallie, etiam post pacem inter ipsos reges dudum factam et iuramentis firmatam, nouiter occuparunt, quod ipsa castrum et uillam eidem regi Portugallie restituat et huius pacem obseruet scribimus, prout continet cedula presentibus interclusa. Cum autem in premissis fauor tuus sit plurimum oportunus, fraternitatem tuam hortamus attentius, tibi nichilominus per apostolica scripta mandantes, quatenus pro nostra et apostolice sedis reuerentia, ac etiam publice utilitatis et tui honoris intuitu, apud eundem regem Castelle et Legionis, uiis et modis de quibus circunspectioni tue uidebitur, ipsum etiam si expediat super hoc per tuas litteras sollicitando quod castrum et uillam predictam eidem regi Portugallie, prout ei scribimus, restituat, etiam huius pacem firmiter obseruet, diligenter insistere sinceritas tua uelit. Datum Auinione, ii nonas decembris, anno secundo.

\section{7}

\section{3, enero 26, Aviñón.}

Gregorio XI exhorta a Enrique II de Castilla a observar la paz con el rey de Portugal, para lo cual le insta a atender las gestiones de su legado el cardenal Guido de Boulogne. 
ASV, Reg. Vat. 269, fol. 120r.

Carissimo in Christo filio Henrico, Regi Castelle et Legionis illustri, salutem et cetera. Nuper displicenter accepimus, et non modicum summus admirati, si relatis nobis ueritas suffragetur, quod quanuis tu et carissimus in Christo filius noster Fernandus, Rex Portugalie illustris, super guerris et discordiis inter uos humani generis inimico procurante dudum exortis, uenerabili fratre nostro Agapito, Ulixbonense, tunc Brixiense episcopo mediante, pacem feceristis, ita quod unus alteri guerram mouere, nisi prius nobis hoc significaret, non deberet siue posset, premissaque firmaueritis propriis iuramentis, prout in capitulis dicte pacis per prefatum episcopum nobis prenotatis plenius continetur, tu tamen et idem rex Portugalie nouam guerram incepistis, uos et subditos ac amicos uestros maximis periculis exponendo, quocura serenitatem tuam rogamus et hortamur attente quatenus, solenter attendens quod sit omista periculis, quantamque discriminam secum trahat huiusmodi dampnosa dissensio, quantumque ex hoc Christi fidelibus contristationis et damni, et infedelibus exaltationis et gaudii materia preparetur, tuumque in mansuetudine animum temperans, pro diuina et apostolice sedis et nostra reuerentia, et etiam tue salutis et honoris intuitu, ab huiusmodi guerra omnino desistas, et dictam pacem sic iuratam et firmatam cum nostro rege Portugalie, cui etiam super hoc scribimus, obserues et per tuos subditos obseruari facias atque mandes, ac uenerabili fratri nostro Guidoni, episcopo Portuensi, apostolice sedis legato, cui etiam super hoc scribimus, aut illi que ad te destinabit, in hiis que pro parte nostra tibi dixerit, adhibeas plenam fidem. In hoc preces nostras taliter impleturus, quod ipse Rex Regum, qui extollit pacificos et deprimit inquietos, tue celsitudinis exaltet solium, prosperitatem adaugeat, ac regnum tuum in transquillitate custodiat, tibique salutis eterne plurima largiatur, nosque et sedes predicta ad omnia que tui honoris et status augmentum respiciunt propensius inclinemur. Datum Auinione, vii kalendas februarii, anno tertio.

\section{8}

\section{3, abril 16, Aviñón.}

Gregorio XI ordena a su legado en España, el cardenal Guido de Boulogne, que proceda contra ciertos eclesiásticos que tramaban la subversión en Castilla.

\section{ASV, Reg. Vat. 265, 122v-123r.}

Venerabili fratri Guidoni, episcopo Portuense, apostolice sedis legato, salutem. Nuper ad nostrum -non sine mentis turbatione- peruenit auditum quod nonnulle persone ecclesiastice, etiam religiose, quique etiam sub diuinis habitibus per regna Castelle et Legionis discurrentes, nonnullos tractatus facere, et diuersas ambaxiatas portare, et conplura alia peragere contra prosperum statum et tranquillum carissimi in Christo filii nostri Henrici, regis Castelle et Legionis illustris, et in subuersionem regnorum predictorum presumunt. Nos igitur, nolentes premissa, que nobis summe displicent, conuentibus oculis pertransire, fraternitati tue, de qua in hiis et aliis specialem in Domino fiduciam obtinemus, per apostolica scripta committimus et mandamus, quatenus de omnibus et singulis personis ecclesiasticis, secularibus et regularibus, etiam si mendicantes fuerint, que in premissis seu aliquo eorundem culpabiles fuerint, ipsas si expedierit capiendo, et carceri mancipando summarie, simpliciter et de plano, ac sine strepitu et figura iudicii, auctoritate apostolica, per te uel alium ministres iustitie complementum, contradictores eadem auctoritate appellatione postposita conpescendo, non obstantibus constitutionibus apostolicis de una et de duabus dietis, ac aliis contrariis quibuscumque, [123r] necnon exemptionibus et aliis quibus ius, priuilegiis, indulgentiis, graciis et litteris apostolicis quibuslibet personis uel ordinibus, communiter uel diuisim, sub quacunque forma uel expressione uerborum ab eadem sede concessis uel imposterum concedendis, etiam si de illis plena et expressa mentio, ac de uerbo ad uerbum in presentibus sit habenda, que, quo, ad hoc alicui in nullo uolumus suffragari. Datum Auinione, xvi kalendas maii, anno tertio.

9

\section{3, abril 21, Aviñón.}

Gregorio XI exhorta a Pedro IV de Aragón a prepararse a hacer la paz con Castilla, y le presenta al legado Guido de Boulogne y al archidiácono de Lérida, Bernardo de Oliva.

\section{ASV, Reg. Vat. 269, fol. $156 \mathrm{v}$.}

Carissimo in Christo filio Petro, Regi Aragonum illustri, salutem et cetera. Alias serenitati tue, tam nos quam frater noster Urbanus papa $\mathrm{V}$, predecessor noster, pro bona pace et concordia inter te et carissimum in Christo filium nostrum Henricum, Regem Castelle et Legionis illustrem, reformanda, pluries scripsimus, et demum propter affectionem specialem quam ad procurandum statum pacificum et tranquillum inter te et ipsum regem Castelle et Legionis habebamus et habemus, uenerabilem fratrem nostrum Guidonem, episcopum Portuensem, apostolice sedis legatum ad partes illas duxerimus destinandum, uerum cum huiusmodi pacis negocium nondum, quod nobis summe displicet, ad finem deuenerit per optatum, et sicut accepimus dictus legatus tractaturus de huiusmodi pacem et concordiam ad loca utrique parti satis accomoda appropinquare debeat infra breue, excellentiam regiam rogamus et hortamur in filio Dei partis, et pro ipsius nomine obsecramus, quatenus tuum in mansuetudine animum properans, pro diuina et apostolice sedis ac nostra reuerentia, ad pacem reformandam, per quam regna crescunt et populi sub tranquillitate proficiunt, cum dicto rege te commitas, in hoc preces nostras taliter impleturus, quod ipse Rex Regum, qui extollit pacificos et deprimit inquietos, tue celsitudinis exaltet solium, prosperitatem adaugeat, ac regnum tuum in tranquillitate custodiat, tibique salutis eterne premia largiatur, nosque, qui te sincere diligimus, eandem celsitudinem tuam dignis in Domino laudibus attollamus, ac uniuersis Christi fidelibus publice letitie consolationem exultantibus animis prebere in Domino ualeamus, et insuper dilecto filio Bernardo 
de Oliuis, archidiacono llerdense, latori presentium, qui tui honoris et commodi feruidus zelator, et in Romana curia procurator tuus existit, que propterea ad te exspeciali confidentia destinamus, in hiis que super premissis et aliis per nos sibi impositis ex parte nostri tibi dicet, adhibere plenam fidem sinceritas tua uelit. Datum Auinione, xi kalendas maii, anno tertio.

10

\section{3, agosto 22, Villeneuve-lès-Avignon.}

Gregorio XI felicita a Carlos II de Navarra por la reciente paz con Castilla, y le exhorta a perseverar en ella.

\section{ASV, Reg. Vat. 269, fol. 203r.}

Carissimo in Christo filio Carolo, Regi Nauarre illustri, salutem et cetera. Deo gratias agimus et laudationum uota debite persoluimus, qui te et carissimum in Christo filium nostrum Henricum, Regem Castelle et Legionis illustrem, prout nuper ad nostrum prouenit auditum, ad bonam reduxit concordiam, ac sinceritati tue congaudemus, qui zelo fidei ac ad nostram et Romane ecclesie deuotionem accensus, pacis consilia iniisti, teque ut carius possimus deprecamur, quatenus huiusmodi pacem Deo placidam et, dante Domino, populo fructuosa, prout plene confidimus, obserues et a tuis subditis facias inuiolabiliter obseruari, ita quod tu et idem Rex Castelle et Legionis in unitate et concordia firmari ualeatis, ut expedit in pacis multitudine delectari: sicque pacis angeli uobis congaudeant, et nos, qui te et ipsum Regem Castelle et Legionis sincere brachiis caritatis amplectimur, in uobis sicut in principibus pacificis et pacis filiis delectabiliter gloriemur. Datum apud Villanouam, Auinionensis diocesis, xi kalendas septembris, anno tertio.

\section{1}

\section{3, agosto 22, Villeneuve-lès-Avignon.}

Gregorio XI felicita a Enrique II de Castilla por el éxito de la misión de sus nuncios contra los clérigos amancebados, le insta a perseverar en la reciente paz con Navarra, y le anima a concluir la paz con Aragón, para lo cual le remite a los oficios de su legado en España, el cardenal Guido de Boulogne.

\section{ASV, Reg. Vat. 269, fols. 203v-204r.}

Carissimo in Christo filio Henrico, Regi Castelle et Legionis illustri, salutem et cetera. Gaudemus et letamur in Domino, qui sic personam tuam gratiose sue benedictionis perfundit, sicque tibi grandem animum prebuit ad sua beneplacita prosequenda, quod tamquam princeps christianissimus eximie deuotionis et illustrium meritorum titulis insignitus, apud ipsum Deum et sedem apostolicam gerens reuerentiam filialem, ac dignitatis regie altitudinem recognoscens Romanam ecclesiam matrem tuam digno semper honore prosequeris, et ad hoc semper intentus existis, ut ecclesia ipsa a noxiis, Deo propitio, preseruetur, et exaltationis suscipiat incrementum. Sane nuper, tam ex uenerabilis fratris nostri Guidonis, episcopi Portuensis, apostolice sedis legati, quam ex dilectorum filiorum Johannis, abbatis monasterii Mansigarnesii, ordinis sancti Benedicti, Tholosane diocesis, et Arnaldi Andree, decani ecclesie Engolismensis, apostolice sedis nuntiorum, litteris intelleximus qualiter propter negotium contra concubinarios Ispanie et aliarum partium per nos eisdem nuntiis comissum, multi contra nos obloquebantur pretendentes litteris falsis quod ad questum pecunie hoc duxeramus ordinandum. Cum autem in partibus illis multi essent ecclesiastici uiri uitam inhonestam et lubricam ducentes, qui per constitutionem bone memorie Petri, episcopi Sabinensis, in partibus illis apostolice sedis legati, non solum eorum beneficiis priuati, sed pluribus erant excommunicationum sententiis et aliis penis in constitutione ipsa continentis irretiti, et propterea ut talium animarum consuleretur saluti, ac in premissis salubriter prouideri ualeret, et etiam ex aliis causis, dictos nuntios ad partes illas cum certis potestatibus duxerimus destinandum, attendentes tamen eximiam deuotionis sinceritatem quam tu, inter ceteros catholicos principes orbis terre, ad nos et eandem Romane ecclesie ut deuotissimus filius gerere comprobaris, et propterea in regnis tuis quacunque dissentionis seu scandali materiam submouere, et in hoc salubriter obuiare uolentes, eisdem nuntiis scribimus, prout continet cedula presentibus interclusa.

Propterea, fili carissime, Deo gratias agimus et laudationum uota debite persoluimus, qui te et carissimum in Christo filium nostrum Carolum, regem Nauarre illustrem, prout nuper ad nostrum peruenit auditum, ad bonam reduxit concordiam, ac sinceritati tue congaudemus, qui zelo fidei ac ad nostram et eiusdem Romane ecclesie deuotionem accensus, pacis consilia iniisti, teque ut carius possumus deprecamur, quatenus huiusmodi pacem Deo placidam et, dante Domino, populo fructuosam, prout plene confidimus, obserues et a tuis subditis facias inuiolabiliter obseruari, ita quod tu et idem rex Nauarre in unitate et concordia firmari ualeatis, ut expedit in pacis multitudine delectari, sicque pacis angeli uobis congaudeant, et nos, qui te et ipsum regem Nauarre sincere brachiis caritatis amplectimur, in uobis sicut in principibus pacificis et pacis filiis delectabiliter gloriemur.

Ceterum, amantissime fili, cum sicut prefatus legatus nobis pluries scripsit, tu, inter ceteros mundi principes, nos et eandem Romanam ecclesiam, prout experientia docet, speciali deuotione prosequaris et libenter nostris et predicte sedis consiliis acquiescas, super quo [204r] tuam prudentiam multipliciter comendamus, excellentiam attentius exhortamur, ac pro speciali munere petimus, quatenus ad bonam pacem et concordiam cum carissimo in Christo filio nostro Petro, Rege Aragonum illustri, dante Domino, adimplendam, super quo aliud eidem excellentie pluries scripsimus, tuum inclines animum, disponas et mentem, ac prefato legato in hiis que super hoc ex parte nostra tibi dicet plenam fidem adhibere sinceritas tua uelit. Datum apud Villanouam, Auinionensis diocesis, xi kalendas septiembris, anno tertio. 
12

1373, diciembre 9, Aviñón.

Gregorio XI presenta a Pedro IV de Aragón a los nuncios que, tras la muerte del legado Guido de Boulogne, proseguirán la negociación de la paz con Castilla.

ASV, Reg. Vat. 269, fol. 241v.

Carissimo in Christo filio Petro, Regi Aragonum illustri, salutem et cetera. Cum dudum, attenta graui discordia qua inter te et carissimum in Christo filium nostrum Henricum, Regem Castelle et Legionis illustrem, humani generis inimicus inuidus, caritatis suscitaret bone memorie Guidonem, episcopum Portuensem, apostolice sedis legatum, pro bona pace inter te et ipsum regem Castelle et Legionis facienda presentialiter duxerimus destinandum, ipseque legatus huiusmodi pacis negotis, quod nobis summe displicet, nondum adimpleto, uiam fuisset uniuerse carnis ingressus, nosque uenerabilibus fratribus nostris Garino, Carnotensi, et Oliverio Bracharensi, Rachanatensi episcopis, qui cum prefato legato ad partes illas accesserant, tractandi bonam pacem et concordiam inter te et prefatum regem Castelle et Legionis, per alias demus nostras litteras potestatem, regalem excellentiam, quam in adimplendis uotis nostris promptam semper inuenimus et paratam, rogamus et hortamur in Domino eam attentius deprecantes ac pro speciali munere postulantes, quatenus pro nostra et apostolice sedis reuerentia, ac tue salutis intuitu, et sicut nobis placere desideras, te ad bonam pacem et concordiam cum dicto Rege Castelle et Legionis tuum inclines animum, disponas et mentem: in hoc preces preces [sic] nostras taliter completurus, quod ipse Rex Regum, qui extollit pacificos et deprimit inquietos, tue celsitudinis exaltet solium, prosperitatem adaugeat, et regnum tuum in tranquillitate custodiat, tibique salutis eterne plurima largiatur, nosque et sedes predicta ad omnia que tui honoris et status augmentum respiciunt propensius inclinemus. Datum Auinione, v idus decembris, anno tertio.

13

1373, diciembre 9, Aviñón.

Gregorio XI pide información a sus nuncios los obispos de Chartres y Recanati acerca del estado de las negociaciones de paz entre Castilla y Aragón, de cuya mediación se han hecho cargo desde el reciente fallecimiento del cardenal Guido de Boulogne, y los anima a llevarlas a buen puerto.

ASV, Reg. Vat. 269, fol. 242r.

Venerabilibus fratribus Garino, Carontensi, et Oliuerio, Rachanatensi episcopis, salutem et cetera. Cum dudum, propter grauem discordiam quam pacis emulus et inuidus caritatis inter carissimos in Christo filios nostros Petrum, Aragonum, ac Henricum, Castelle et Legionis reges illustres, suscitarat, bone memorie Guidonem, episcopum Portuensem, apostolice sedis legatum, pro bona pace et concordia inter reges ipsos facienda, ad partes illas duxerimus destinandum, ipseque Portuensis episcopus, cum quo illuc accessistis, huiusmodi pacis negotio, quod nobis summe displicet, nondum adimpleto, sicut Domino placuit uiam fuerit uniuerse carnis ingressus, nosque de tractatu dicte pacis et qualiter negotium se liceat non sumus aliquatenus informati, fraternitatem uestram hortamur attentius, uobis nichilominus per apostolica scripta mandantes, quatenus qualiter negotium et tractatus dicte pacis nobis quantocius rescribere non tardetis. Preterea cum huiusmodi pacis negotium inter cetera nobis incumbentia negotia summe cordi nobis sit, et propterea prefatis regibus scribamus, prout continet cedula presentibus interclusa, eandem fraternitatem uestram iterum exhortamur, uobis nichilominus tenore presentium demandantes, quatenus si uobis uideatur quod in tractatu dicte pacis perficere ualeatis in hoc iuxta potestatem, quam etiam uobis mittimus per alias nostras litteras presentibus interclusas, omni mora cessante procedatis, quia statim, uestra relatione audita, si proficere posse credideritis litteras de stipendiis condecentibus a tempore quo in hoc laborare inceperitis uobis quantocius transmittemus super premissis, etiam uenerabili fratri nostro ... [sic], episcopo llerdensi scribimus, prout continet alia cedula presentibus etiam interclusa. In hoc tamen uos cautos esse uolumus, quod prefatas litteras que predictis diriguntur regibus nisi ad tractatum pacis inter eos incipiatis procedere nullatenus presentetis seu presentari permittatis. Datum ut supra. 